Neurobiology of disease - Regular article

\title{
Effects of L-DOPA and STN-HFS dyskinesiogenic treatments on NR2B regulation in basal ganglia in the rat model of Parkinsons disease
}

\author{
Adrien Quintana ${ }^{1,2}$, Véronique Sgambato-Faure ${ }^{1,4}$ and Marc Savasta ${ }^{1,2,3^{*}}$ \\ ${ }^{1}$ Institut National de la Santé et de la Recherche Médicale, Unité 836, Grenoble Institut des \\ Neurosciences, Dynamique et Physiopathologie des Ganglions de la Base, Grenoble F- \\ 38043, France \\ ${ }^{2}$ Université Joseph Fourier, Grenoble F- 38042, France \\ ${ }^{3}$ Centre Hospitalier Universitaire de Grenoble, F-38043 Grenoble, France \\ 4 Present address: Centre de Neuroscience Cognitive, Centre National de la Recherche \\ Scientifique UMR 5229-Université de Lyon I, Bron F-69675 Cedex France
}

"Correspondence should be addressed to Dr Marc Savasta, INSERM U836, Grenoble Institute of Neuroscience, Dynamic and Physiopathology of Basal Ganglia, University Joseph Fourier - Site Santé La Tronche - BP 170, 38042 Grenoble, France. Phone: 334565206 75, Fax: 334565206 69. E-mail address: marc.savasta@ujf-grenoble.fr Dr Veronique Sgamabto-Faure, co-corresponding author. Email address: veronique.sgambato-faure@isc.cnrs.fr

Abbreviated title: NR2B hyperphosphorylation driven by L-DOPA and STN-HFS Number of figures: 8; Number of tables: 1; Number of pages: 36; Number of words: 6707 (Abstract, 188; Introduction, 495 and Discussion, 1886)

Acknowledgments: This work was supported by the Institut National de la Santé et de la Recherche Médicale, le Ministère de la Recherche et des Nouvelles Technologies (Agence Nationale pour la Recherche, Grant no. ANR-05-NEUR-013-01), Région Rhône-Alpes (Cluster no.11), Association France Parkinson and Fondation NRJ-Institut de France. We thank, Drs Jean-Antoine Girault and Denis Hervé for the generous gift of NR2B antibody; Dr Carole Carcenac, for her invaluable assistance for morphological studies and quantitative measurements, and Dr Sabrina Boulet, for critical reading of this manuscript.

\section{List of abbreviations:}

6-OHDA, 6-hydroxydopamine; AIMS, abnormal involuntary movements; DA, dopamine; EP, entopeduncular nucleus; L-DOPA, L-3,4-dihydroxyphenylalanine; LID, L-DOPA-induced dyskinesia; NMDA, N-methyl-D-aspartate; PD, Parkinson S disease; SNc, substantia nigra pars compacta; SNr, substantia nigra pars reticulata; STN-HFS, high frequency stimulation of the subthalamic nucleus; $\mathrm{TH}$, tyrosine hydroxylase. 


\begin{abstract}
Dyskinesia is a major side effect of chronic levodopa (L-DOPA) administration, the reference treatment for Parkinsons disease (PD). High-frequency stimulation of the subthalamic nucleus (STN-HFS) alleviates parkinsonian motor symptoms and indirectly improves dyskinesia by decreasing L-DOPA requirement. However, inadequate stimulation can also trigger dyskinetic movements in PD patients and animal models. Here, we investigated the possible association between L-DOPA- and STN-HFS-induced dyskinesia and regulation of the NR2B subunit of NMDA receptors in the rodent model of PD. We subjected 6-OHDA-lesioned rats to HFS for one hour, at an intensity triggering forelimb dyskinesia. Other 6-OHDA-lesioned rats were treated with chronic high doses of L-DOPA for ten days, to induce abnormal involuntary movements. The 6-OHDA lesion regulated NR2B only in the SNr, where the activation of NR2B was observed (as assessed by phosphorylation of the $\mathrm{Tyr}^{1472}$ residue). Both STN-HFS and L-DOPA dyskinesiogenic treatments induced NR2B activation in the STN and EP, but only L-DOPA triggered NR2B hyperphosphorylation in the striatum. Finally, the use of CP-101,606 exacerbated L-DOPAinduced motor behavior and associated NR2B hyperphosphorylation in the striatum, STN and EP. Thus, NR2B activation in basal ganglia structures is correlated with dyskinesia.
\end{abstract}

Keywords: Parkinsons disease, dyskinesia, 6-OHDA lesion, L-DOPA, high-frequency stimulation, glutamate, NMDA receptors, NR2B, basal ganglia. 


\section{Introduction}

Levodopa (L-DOPA) administration remains the best treatment for alleviating the motor symptoms of Parkinsons disease (PD) (Birkmayer and Hornykiewicz, 1961). However, its long-term use is associated with motor fluctuations and L-DOPA-induced dyskinesia (LID; Barbeau, 1969; Rascol and Fabre, 2001; Ahlskog and Muenter, 2001). High-frequency stimulation of the subthalamic nucleus (STN-HFS) indirectly improves LID in parkinsonian patients, essentially by decreasing the dose of L-DOPA required (Krack et al., 1999; 2003; Toda et al., 2004). However, STN-HFS may also have prodyskinetic effects in PD patients (Limousin et al., 1996; Moro et al., 2002) and animal models of PD (Beurrier et al., 1997; Salin et al., 2002; Boulet et al., 2006). Models of stimulation-induced dyskinesia have been used to improve our understanding of the mechanisms of STN-HFS and the physiopathology of dyskinesia. Unlike LID, the dyskinetic movements induced by HFS are transient, consistent with the occurrence of rapid adaptive mechanisms, with glutamate receptors potentially involved in this plastic response (Sgambato-Faure and Cenci, 2012).

For many years, N-methyl-D-aspartate (NMDA) glutamatergic receptors have been the most popular target for the development of antidyskinetic drugs (Chase and Oh, 2000), such as amantadine, a weak non-competitive NMDA receptor antagonist that reduces dyskinesia in PD patients (Del Dotto et al., 2001) and animal models (Bibianni et al., 2005; Dekundy et al., 2007). Several studies have highlighted a possible role for the NR2B subunit of the NMDA receptor in dyskinesia in PD patients (Calon et al., 2003) or parkinsonian animals (Calon et al., 2002; Oh et al., 1998; Chase and Oh, 2000; Dunah et al., 2000; Hurley et al., 2005). The NR2B-selective antagonist CP-101,606 was shown to decrease peak-dose LID in a small proof-of-principle study in PD patients (Nutt et al., 2008). We have also shown that the forelimb dyskinesia induced by STN-HFS in the normal rat is linked to NR2B hyperphosphorylation and attenuated by CP-101,606 (Quintana et al., 2010). In this study, we aimed to extend this previous work by using the rodent model of Parkinsons disease (the 6-OHDA-lesioned rat) and by asking whether or not these two dyskinesia models (STN-HFSinduced or L-DOPA-induced) share some common neurobiological basis. We have chosen to investigate in all the basal ganglia structures, not only the striatum, the impact of L-DOPA and STN-HFS dyskinesiogenic treatments on NR2B, a glutamatergic target, whose regulation has been clearly associated to the maladaptative response to L-DOPA in the striatum (Calon et al., 2002; 2003; Oh et al., 1998; Chase and Oh, 2000; Dunah et al., 2000; Hurley et al., 2005; Nutt et al., 2008; Quintana et al., 2010) but not in the other basal ganglia structures. . We found that L-DOPA induced NR2B hyperphosphorylation in the striatum ipsilateral to the 6-OHDA lesion, whereas STN-HFS did not. Both dyskinesiogenic treatments induced NR2B hyperphosphorylation in the ipsilateral STN and, bilaterally, in the entopeduncular nucleus (EP). Finally, the combination of CP-101,606 with L-DOPA caused an exacerbation of L-DOPA-induced motor behavior associated with higher levels of NR2B hyperphosphorylation in the ipsilateral striatum, STN and EP. 


\section{Materials and Methods \\ Animals}

Experiments were performed on 34 male Sprague Dawley rats (Janvier, Le Genest-SaintIsle, France) weighing $180 \mathrm{~g}$ (for lesion surgery) to $300 \mathrm{~g}$ (for electrode implantation, STNHFS and pharmacological treatment), housed under standard laboratory conditions (12 h light $/ 12 \mathrm{~h}$ dark cycle, $24^{\circ} \mathrm{C}$ ) with food and tap water provided ad libitum. Protocols were carried out in accordance with the European Community Council Directive of 24 November 1986 (86/609/EEC) for the care of laboratory animals and with French Ministry of Agriculture regulations (authorization $N^{\circ} 38-09-17$ ). Animals were grouped by protocol, naive (control group, $n=7$ ), rats with unilateral depletion of the dopaminergic system (6-OHDA group, $n=$ 6 ), 6-OHDA subjected to HFS of the STN (HFS group, $n=9$ ), 6-OHDA rats treated by chronic L-DOPA administration (L-DOPA group, $n=6$ ) and 6-OHDA rats treated by chronic L-DOPA and CP-101,606 administration (CP group, $n=6$ ).

\section{Lesion surgery}

All animals $(n=27)$ were first treated with desipramine- $\mathrm{HCl}(25 \mathrm{mg} / \mathrm{kg}$, s.c., Sigma-Aldrich, Saint Quentin-Fallavier, France) to protect noradrenergic neurons and anesthetized with a mixture of ketamine $(100 \mathrm{mg} / \mathrm{kg})$ and xylazine $(10 \mathrm{mg} / \mathrm{kg})$. They were then being secured in a Kopf stereotaxic apparatus (Phymep, Paris, France). We injected $9 \mu \mathrm{g}$ of 6-OHDA-HCl (6hydroxydopamine hydrochloride, Sigma-Aldrich, Saint Quentin-Fallavier, France) dissolved in $3 \mu \mathrm{l}$ of sterile $0.9 \% \mathrm{NaCl}$ and $0.1 \%$ ascorbic acid, at a flow rate of $0.5 \mu \mathrm{l} / \mathrm{min}$ into the left substantia nigra pars compacta (SNc). The stereotaxic coordinates of the injection site relative to the bregma were as follows: anteroposterior (AP), $-5.3 \mathrm{~mm}$; lateral $(\mathrm{L}),+2.2 \mathrm{~mm}$ and dorsoventral (DV), $-7.5 \mathrm{~mm}$, with the incisor bar at $3.3 \mathrm{~mm}$ below the interaural plane. All stereotaxic coordinates are cited according to the stereotaxic atlas of Paxinos and Watson (1982). Animals were kept warm after the injection and allowed to recover from anesthesia.

\section{Pharmacological treatment and assessment of L-DOPA-induced motor behavior}

All drugs were purchased from Sigma, with the exception of CP-101,606, which was generously provided by Pfizer. Three weeks after lesioning, 6-OHDA-lesioned rats were treated with L-DOPA (L-3,4-dihydroxyphenylalanine methyl ester hydrochloride at $50 \mathrm{mg} / \mathrm{kg}$ plus $10 \mathrm{mg} / \mathrm{kg}$ benserazide subcutaneously, $n=6$, L-DOPA group) twice daily for 10 days as previously described (Sgambato-Faure et al., 2005; El Atifi-Borel et al., 2009, Quintana et al., 2010). As we were interested in only rats that developed significant AIM scores, the dose of $50 \mathrm{mg} / \mathrm{kg}$ for L-DOPA was chosen as it allows in our model the induction of dyskinesia in all 6-OHDA-lesioned rats, while a lower dose $(10 \mathrm{mg} / \mathrm{kg}$ ) does not (see in Sgambato-Faure et al., 2005). Of note, it has been shown that the dose of L-Dopa is a significant risk factor for the development of LIDs (Putterman et al., 2007). Rats from the CP group $(n=6)$ were also treated with L-DOPA twice daily for 10 days, but they also received $3 \mathrm{mg} / \mathrm{kg} \mathrm{CP-101,606} 15$ minutes before each L-DOPA injection. Behavioral analyses were conducted during six observation sessions, at two-day intervals. Each session was 100 minutes long, started 20 minutes after the L-DOPA administration and consisted of five two-minute observation periods. The severity of dyskinesia (forelimb, orolingual or axial, also referred to as abnormal involuntary movements (AIMs)) was evaluated on a scale from 0 to 4 defined by the group of Cenci (Cenci et al., 1998; Andersson et al., 1999). The total AIMs score per session was obtained by summing the scores of each AIM during all the observation periods. Contralateral rotations were evaluated separately.

\section{Electrode implantation and STN-HFS}

6-OHDA-lesioned rats $(n=9)$ were anesthetized by isoflurane inhalation (Aerane, Laboratoires Belamont, Neuilly sur Seine, France) and mounted in a stereotaxic frame (David Kopf Instruments, Phymep, Paris, France). The dorsal skull was exposed and holes were drilled to facilitate the unilateral implantation of the monopolar electrode into the left STN at the following coordinates, according to the atlas of Paxinos (relative to bregma): AP = 
$-3.7 \mathrm{~mm}, \mathrm{~L}=2.4 \mathrm{~mm}$, DV $=-7.8 \mathrm{~mm}$, as previously described (Quintana et al., 2010). The electrode consisted of a platinium-iridium wire insulated with Teflon (wire diameter, $110 \mathrm{~mm}$ insulated, $76 \mathrm{~mm}$ bare) but with an exposed end (length $400 \mathrm{~mm}$ ) (Phymep, Paris, France). The inserted electrode served as the negative stimulation pole and a screw fixed on the skull behind the electrode was used as the positive pole. The stimulation electrode was fixed to the skull with dental cement (Dentalon Plus; Phymep, Paris, France). Two to three days after surgery, STN-HFS was carried out to determine the intensity threshold for the induction of forelimb dyskinesia in each animal, in conditions of free movement (Boulet et al., 2006, Quintana et al., 2010). The frequency and pulse width were set at $130 \mathrm{~Hz}$ and $60 \mathrm{~ms}$, respectively, and intensity was gradually increased from 0 to $250 \mathrm{~mA}$. Once this threshold had been determined, the animals were allowed to rest for one day. The next day, they were subjected to stimulation for one hour at an intensity fixed at the threshold for forelimb dyskinesia, as previously reported (Boulet et al., 2006, Quintana et al., 2010). Stimuli were delivered with an A310 acupulser and an A360 stimulus isolator (both purchased from WPI, Stevenage, UK). At the end of the stimulation, a small electrical lesion was generated, for visualization of the position of the tip of the electrode in the STN. All rats were killed immediately after the end of stimulation.

\section{Morphological studies Tissue preparation}

One hour after the last L-DOPA injection or the start of stimulation, the animals were given a lethal dose of chloral hydrate and killed by intracardiac perfusion of Ringer solution, followed by $4 \%$ paraformaldehyde in $0.1 \mathrm{M} \mathrm{Na}_{2} \mathrm{HPO}_{4} / \mathrm{NaH}_{2} \mathrm{PO}_{4}$ buffer, $\mathrm{pH} 7.5$ (phosphate buffer). Brains were removed and post-fixed by incubation in the same fixative solution for $2 \mathrm{~h}$, washed overnight in $15 \%$ sucrose in $0.1 \mathrm{M}$ phosphate buffer and frozen in cooled isopentane $\left(-20^{\circ} \mathrm{C}\right)$. Coronal sections $(30 \mu \mathrm{m})$ were cut on a cryostat and stored at $20^{\circ} \mathrm{C}$ in a solution containing $30 \%$ ethylene glycol, $30 \%$ glycerol, $0.1 \mathrm{M}$ phosphate buffer, and $0.1 \%$ diethyl pyrocarbonate (DEPC) until processing.

\section{Histological control of electrode placement and 6-OHDA lesion}

The location of the stimulating electrode in the STN of HFS group was examined on cresylviolet-stained sections. Briefly, free-floating sections $(30 \mathrm{~mm})$ were rinsed in Tris buffer (TB; $0.25 \mathrm{M}, \mathrm{pH} 7.5$ ) and mounted on gelatin-coated slides. Slides were briefly washed in distilled water and immersed in a $0.3 \%$ cresyl violet solution for 3 minutes. They were then dehydrated through a series of alcohol solutions and cleared by incubation in histolemon for light microscopy. The loss of DA cells and terminals was assessed by immunohistochemistry for TH (tyrosine hydroxylase) as previously described (Sgambato-Faure et al., 2005). Animals showing a misplaced electrode or a reduction of $\mathrm{TH}$ staining inferior of $80 \%$ were not included in the experimental groups presented above.

\section{Immunohistochemistry}

Free-floating sections were rinsed in Tris-buffered saline (TBS; $0.25 \mathrm{M}$ Tris and $0.25 \mathrm{M} \mathrm{NaCl}$, $\mathrm{pH} 7.5$ ), incubated for 5 minutes in $3 \% \mathrm{H}_{2} \mathrm{O}_{2}$ and $10 \%$ methanol in TBS and rinsed three times, for 10 minutes each, in TBS. They were then incubated for 15 minutes in $0.2 \%$ Triton $\mathrm{X}-100$ in TBS and rinsed three times in TBS. They were incubated with the primary antibody (anti-TH, anti-NR2B or anti-phospho-NR2B) for 72 hours at $4^{\circ} \mathrm{C}$. The primary antibodies used in this study were: a rabbit polyclonal antibody against phospho-Tyr ${ }^{1472}$-NR2B (catalog \# ABC72-00135; AbCys, Paris, France) used at a dilution of 1/300 (Quintana et al., 2010); a NR2B antibody used at 1/700 (generously provided by Drs J.A. Girault and Denis Hervé; Institut du Fer à Moulin, Inserm \& UPMC, Paris) (Menegoz et al., 1995; Quintana et al., 2010), and an anti-TH (catalog \# VMA5280; AbCys, Paris, France) antibody used at 1/12500. Sections were rinsed three times in TBS, and incubated for 2 hours at $4^{\circ} \mathrm{C}$ with the corresponding secondary antibody in TBS (biotinylated anti-Rabbit IgG (for both P-NR2B and NR2B) or biotinylated anti-mouse (for TH) used at a dilution 1/500 (Catalog \# BA- 1000 or BA-2000, respectively fromVector Laboratories, Abcys, Paris, France). Sections were 
washed and incubated for 90 minutes at room temperature in avidin-biotin-peroxidase complex (ABC) solution (final dilution 1/50) (catalog \# PK 4000; Vector Laboratories, Abcys, Paris, France). The sections were then rinsed twice in TBS and twice in TB (0.25 M Tris, pH 7.5), for 10 minutes each, placed in $0.1 \%$ 3,3-diaminobenzidine (DAB; $50 \mathrm{mg} / 100 \mathrm{ml}$ ) in TB and developed by incubation with $\mathrm{H}_{2} \mathrm{O}_{2}(0.02 \%)$.

\section{Data analysis}

Immunostained sections were examined under a light microscope and digitized at various magnifications, with a computerized image analyzer (Analysis, Soft Imaging System, Munster, Germany). Exposure, luminosity and contrast parameters were kept constant within each individual immunohistochemistry experiment. The optical density of immunoreactive signals for P-NR2B, NR2B and TH was determined, as previously described (Peretti-Renucci et al., 1991; Sgambato et al., 1998). Measurements were made with Autoradio V4.03 software (SAMBA Technologies, Meylan, France) for the striatum, the STN, the EP and the SNr. A background value was determined for each section by measuring optical density in the corpus callosum (which was not immunolabeled). This value was systematically subtracted from the optical density obtained for the structures of interest. Histograms show mean \pm standard error of the mean. One-way ANOVA (with [side] as a factor) was used for the analysis of differences in the expression of NR2B and P-NR2B between the two hemispheres, in animals from a given group. Two-way ANOVA (with [lesion] and [striatal region]; [treatment] and [striatal region]; [treatment] and [side] as factors) was used for the analysis of differences in NR2B and P-NR2B expression between treatments (respectively 6OHDA vs. control; L-DOPA vs. control and 6-OHDA; HFS vs. control and 6-OHDA). Statistical significance was assessed in a post-hoc Newman-Keuls multiple comparison test. 


\section{Results}

\section{Control of the extent of 6-OHDA-induced denervation and electrode location}

We tested our hypothesis that NR2B is critically associated with forelimb dyskinesia (Quintana et al., 2010) by carrying out this study in a rodent model of Parkinsons disease, 6-OHDA lesioned rats - and analyzing potential changes in NR2B levels (total or phosphorylated on the tyrosine 1472 residue) in the network of basal ganglia in response to two dyskinesiogenic treatments: acute STN-HFS and chronic L-DOPA. All 6-OHDA-lesioned animals presented a substantial loss of TH immunostaining in the ipsilateral SNc and the striatum, as shown by comparisons with the contralateral side or to control animals (Figure $1 \mathrm{~A}, \mathrm{~B}, \mathrm{C} ; p<0.001)$. An analysis of densitometric measurements of $\mathrm{TH}$ immunostaining showed an absence of statistical difference between the 6-OHDA, HFS or L-DOPA groups. As expected, all displayed strong DA denervation. Panels $D$ and $E$ on Figure1 illustrate the correct location of the stimulation electrode within the STN ipsilateral to the 6-OHDA lesion. No major tissue damage was observed in the structure after stimulation for one hour.

\section{Analysis of the motor behavior induced by STN-HFS or pharmacological treatment}

Consistent with our previous findings (Boulet et al., 2006; Quintana et al., 2010), acute STN-HFS triggered forelimb dyskinesia with an intensity threshold between 100 and $200 \mu \mathrm{A}$ (data not shown). The induction of such dyskinetic movement is transient and cannot be maintained by increasing stimulation intensity because this led to the induction of contralateral rotations (data not shown). Thus, all the animals of the HFS group $(n=9)$ underwent stimulation for one hour at $100 \mu \mathrm{A}$ to $200 \mu \mathrm{A}$.

The severity of AIMs in L-DOPA-treated animals gradually increased during the treatment (Figure 2A; $(p<0.05)$. Figure 2B shows the distribution of the various subtypes of dyskinesia during treatment. Orolingual and forelimb dyskinesia first occurred on day 2 and were followed by axial dyskinesia on day 8 . Forelimb dyskinesia accounted for more than 60 $\%$ of the AIMs on the last day of treatment. Interestingly, no contralateral rotations were induced in this group, a result consistent with our previous findings (Sgambato-Faure et al., 2005).

\section{Effect of the 6-OHDA lesion on levels of NR2B and P-NR2B expression in the striatum, STN, EP and SNr}

We analyzed the impact of the 6-OHDA lesion on the amounts of the total and phosphorylated forms of NR2B in the striatum, subdivided into medial and lateral parts, the STN, the EP and the SNr (Table 1). In the striatum, the expression of NR2B levels were similar in the two hemispheres regardless of the striatal region considered and no significant difference was observed between the 6-OHDA and control groups NR2B levels were also similar in the ipsilateral and contralateral STN (Table 1 and Figure 4E and $\mathrm{H}$ ), in the EP (Figure 5, panels $\mathrm{D}, \mathrm{D} \square$ and $\mathrm{H}$ ) and in the SNr (Table 1 and Figure 6, panel $\mathrm{E}$ ). Moreover, two-way ANOVA confirmed that these levels were closed to those obtained in the control group, either in the STN EP or in the SNr (Table 1).

The 6-OHDA lesion also had no effect on the levels of P-NR2B in the various parts of the striatum (Table 1 and Figure 3, panels $A$ and D), STN (Table 1 and Figure 4A, D) and EP (Table 1 and Figure 5, panels $A, A \sqcap$ and $G$ ). Two-way ANOVA showed that P-NR2B levels were similar in the 6-OHDA and control groups (Table 1), either in the striatum, the STN or the EP (Table 1). The only difference between these two experimental groups was found in the SNr ipsilateral to the lesion, where P-NR2B levels were much higher after 6-OHDA (+ $150 \%, p<0.01$, Table 1 and Figure 6, panels $A, A$ and $D$ ).

\section{Effect of dyskinesiogenic treatment on levels of NR2B and P-NR2B expression in the striatum}

We then investigated the impact of STN-HFS and L-DOPA on NR2B and P-NR2B levels in the striatum (Figure 3). No difference in NR2B immunolabeling was observed 
between the lateral and the medial parts of the striatum after STN-HFS or L-DOPA treatment ipsilaterally or contralaterally (data not shown).

Similar results were obtained for P-NR2B levels after STN-HFS (Figure 3B and D). PNR2B levels were similar in the lateral and medial parts of the striatum of animals from the HFS group

Unlike HFS, chronic L-DOPA treatment strongly increased P-NR2B levels in the lateral part of the ipsilateral striatum $(p<0.001$; Figure $3 C$ and $D)$, consistent with our previous findings (Quintana et al., 2010). This increase was specific to the lateral region compared to the medial one, and was detected only in the ipsilateral side compared to the contralateral one. Post hoc analysis demonstrated that P-NR2B levels in the striatum were significantly higher in the L-DOPA group than in the control and 6-OHDA groups (both $p<$ 0.001 ; L-DOPA vs. control: $+215 \%$, Figure 3D).

\section{Effect of dyskinesiogenic treatment on levels of P-NR2B and NR2B in the STN}

STN-HFS evoked a strong increase in P-NR2B levels in the ipsilateral STN, as shown by comparison with the contralateral side $(p<0.01$ Figure $4 \mathrm{~B}$ and $\mathrm{D})$. Post-hoc analysis revealed that P-NR2B levels in the ipsilateral STN in the HFS group were significantly higher than those in the control and 6-OHDA groups (HFS vs. control: $+190 \% ; p=0.001$; Figure $4 A, B$ and D). HFS had no effect on P-NR2B levels in the contralateral STN.

Interestingly, L-DOPA treatment also led to an increase in P-NR2B levels on the ipsilateral side $(+160 \% p<0.05$; Figure 4C, D).

STN-HFS did not alter NR2B levels (Figure 4, panels $F$ and $H$ ). Ipsilateral and contralateral NR2B levels remained the same and two-way ANOVA identified no significant differences between the control, 6-OHDA and HFS groups.

L-DOPA treatment resulted in no significant difference in NR2B levels between the ipsilateral and contralateral STN. Post-hoc analysis showed that NR2B levels in the ipsilateral STN were significantly higher in the L-DOPA group than in the control group $(+240$ $\% ; p=0.013$, Figure 4H). No difference in NR2B levels on the contralateral side was found between groups.

\section{Effect of dyskinesiogenic treatment on P-NR2B and NR2B levels in the EP}

After STN-HFS, P-NR2B levels were similar in the ipsilateral and contralateral EP $p=$ 0.577; Figure 5, panels $B, B$ and G)., Post-hoc analysis revealed that P-NR2B levels in the ipsilateral EP were significantly higher in the HFS group than in the control and 6-OHDA groups ( $p=0.023$ and $p=0.05$, respectively, SHF vs. control: $+190 \%)$ whereas a significant increase on the contralateral side was observed only in comparison with the control group ( $p$ $=0.05$; SHF vs. control: $+180 \%$, but not for comparisons with the 6-OHDA group $(p=$ $0.066)$.

Similarly chronic L-DOPA also induced a strong and bilateral increase of P-NR2B levels (Figure 5, panels $C, C$ and $G$ ). Two-way ANOVA revealed an effect treatment but no interaction between treatment and side Entopeduncular levels of P-NR2B were significantly higher in the L-DOPA group than in the control and the 6-OHDA groups for both the ipsilateral $(p=0.001$ and $p=0.003$, respectively L-DOPA vs. control: $+230 \%)$ and contralateral ( $p=0.009$ and $p=0.03$, respectively, L-DOPA vs. control: $+210 \%$; Figure $5 G)$ sides. No significant difference was detected between the two hemispheres in the L-DOPA group (Figure 5C-C).

STN-HFS and L-DOPA had no effect on NR2B levels in the EP (Figure 5E, F and H). NR2B levels remained similar on the ipsilateral and contralateral sides and in the various experimental groups, as confirmed by two-way ANOVA analyses (Figure $5 \mathrm{H}$ ).

\section{Effect of dyskinesiogenic treatment on levels of NR2B and P-NR2B expression in the $\mathrm{SNr}$}

We have shown that the 6-OHDA lesion is associated with the induction of P-NR2B in the ipsilateral SNr (Table 1 and Figure 6). No further increase was observed following STN- 
HFS or L-DOPA and no difference of NR2B levels in the contralateral SNr was observed between groups.

Neither STN-HFS nor L-DOPA affected the amount of NR2B (Figure 6E). NR2B levels remained similar on the ipsilateral and contralateral sides after HFS. They did not differ from those in the control and 6-OHDA groups, as confirmed by two-way analyses.

\section{Effect of a combination of CP-101,606 and L-DOPA on motor behavior and NR2B activation in the basal ganglia}

We have previously shown that a selective NR2B antagonist, CP-101,606, could decrease the forelimb dyskinesia evoked by STN-HFS (Quintana et al., 2010). We investigated here the impact of CP-101,606 administration on the motor behavior driven by L-DOPA (Figure 7) and on total and phosphorylated NR2B levels in the basal ganglia (Figure 8). Total AIMs score increased gradually with treatment duration (Figure 7). Post-hoc analysis showed a significantly earlier and larger increase in total AIMs in the CP group $(p<$ 0.01 ) than in the L-DOPA group (Figure 7A). Animals from the CP group developed severe axial and forelimb dyskinesia after as little as two days of treatment (Figure 7B). On day 8, we evaluated the temporal decay of AIMs during an observation period. Post-hoc comparison showed that the AIMs were significantly more severe in the CP group than in the L-DOPA group $(p<0.01)$ (Figure 7C). Finally, animals from the L-DOPA group displayed no rotational behavior, whereas animals from the CP group displayed severe contralateral rotations (Figure 7D). Along these behavioral changes driven by the combined administration of CP-101,606 and L-DOPA, we have observed significant changes regarding the expression of total and phosphorylated NR2B in the basal ganglia (Figure 8). P-NR2B was increased not only in the lateral part of the ipsilateral striatum, but also in its medial part (Figure 8A). PNR2B was also enhanced in the ipsilateral STN and EP (Figure 8C, D). 


\section{Discussion}

Three key findings emerged from this in vivo study on parkinsonian rats. First, DA neuron lesions affected NR2B regulation in the SNr, but not in the other structures of the basal ganglia. Second, only the L-DOPA dyskinesiogenic treatment induced hyperphosphorylation of the $\operatorname{Tyr}^{1472}$ residue of $\mathrm{NR} 2 \mathrm{~B}$, in the striatum ipsilateral to the 6OHDA lesion, whereas both L-DOPA and STN-HFS dyskinesiogenic treatments induced NR2B hyperphosphorylation in the ipsilateral STN and bilaterally in the EP, but not in the SNr. Third, CP-101,606 exacerbated L-DOPA-induced motor behavior and increased NR2B hyperphosphorylation in the ipsilateral striatum, STN and EP.

\section{DA neuron lesions affect NR2B regulation only in the SNr}

Dopamine loss increases the spontaneous release of glutamate in the ipsilateral striatum (Lindefors and Ungerstedt, 1990; Jonkers et al., 2002, Bruet et al., 2003), reflecting enhanced activity of the glutamatergic corticostriatal neurons (Calabresi et al., 1993; Gubellini et al., 2002). Studies of the expression of NMDA subunits in the striatum have given conflicting results, some reporting an increase (Wüllner et al., 1994), others a decrease (Porter et al., 1994; ODell and Marshall, 1996) and still others no change (Calon et al., 2002) in levels of the NMDA receptor, suggesting that mechanisms other than the simple regulation of subunit expression may be involved in the adaptation of the glutamatergic system to the dopaminergic denervation state. Indeed, changes to the trafficking of the NR2B subunit between subcellular compartments have been found (Dunah et al., 2000; Hallet et al., 2005) and are associated with an increase in the phosphorylation of tyrosine residues (Menegoz et al., 1995; Oh et al., 1998). However, few studies have focused on these molecular changes in other structures of the basal ganglia, even though dopaminergic depletion induces an increase in the activity of the projecting glutamatergic neurons from the STN (Hirsch et al., 2000). In the SNr and the EP, Porter and coworkers (1994) described a decrease in the number of AMPA receptors, with no change in the expression of NMDA receptors. No changes were found in the STN (Blandini et al., 2001). Our results confirm these observations, as we observed no modification of NR2B expression in these structures. However, we did detect NR2B hyperphosphorylation in the SNr, but not in the striatum. This finding may appear to conflict with the findings of Dunahs group, but we were unable to determine the proportion of receptors in individual subcellular compartments with our experimental protocol, and our findings may therefore be seen as consistent with the lack of change in the unfractionated homogenates in these previous studies.

\section{Patterns of NR2B activation in response to the L-DOPA and STN-HFS dyskinesiogenic treatments}

Both L-DOPA and STN-HFS induced NR2B hyperphosphorylation in the STN and $E P$, but not in the SNr, whereas L-DOPA induced hyperphosphorylation of this subunit only in the striatum. The dyskinesiogenic effect of STN-HFS on NR2B regulation is therefore similar in hemiparkinsonian and naive rats (Quintana et al., 2010). The finding that both LID and STN-HFS-induced dyskinesia are linked to an increase in the tyrosine phosphorylation of NR2B in the STN-EP network (Quintana et al., 2010 and data presented here) highlights the pathophysiological importance of this pathway in the genesis of dyskinesia. The close association of the EP (GPi in primates) with LID (Aubert et al., 2007; Lacombe et al., 2009) is consistent with the potent antidyskinetic effects of GPi-HFS in parkinsonian patients. An involvement of the STN efferent pathways is also consistent with previous data for a rat model of LID, showing that dyskinesia severity is positively correlated with the levels of c-fos (Soghomonian, 2006) and preproenkephalin-B (encoding dynorphin) mRNA (Aubert et al., 2007) in the STN. This work also sheds light on the different roles of the two output structures of the basal ganglia in akinesia and dyskinesia. Abnormal involuntary movements are similar in both cases and seem to be linked to the indirect pathways between the striatum and the EP after a relay in the STN, whereas the 6-OHDA lesion (which is known to be responsible for akinesia) is associated with changes in the SNr. Recent studies have 
confirmed this hypothesis, by showing that the lesioning or HFS of the GPi improves dyskinesia in parkinsonian patients (Bejjani et al., 1997; Yelnik et al., 2000). The chronic administration of L-DOPA at doses inducing dyskinesia reduces Col expression in the EP (Lacombe et al., 2009) and the firing frequency of GPi neurons (Boraud et al., 1998; 2001). By contrast, therapeutic STN-HFS reverses the 6-OHDA-induced changes in Col expression in the SNr, but not in the EP (Lacombe et al., 2009). Lesioning of the STN induces a larger decrease in GAD67 expression and carbohydrate metabolism in the SNr than in the GPi (Guridi et al., 1996; Su et al., 2001). Lacombe and coworkers (2009) demonstrated an inverse correlation between Col expression levels in the EP and the striatal expression of dynorphin, a molecular marker of dyskinesia in animals and parkinsonian patients (Cenci et al., 1998, 2007; Aubert et al., 2007). No such correlation was observed in the SNr. Finally, akinesia severity is correlated with Col and GAD67 levels in the SNr (Bacci et al., 2004; Salin et al., 2002).

\section{CP-101,606 exacerbates L-DOPA-induced motor behavior and NR2B hyperphosphorylation}

L-DOPA induced an increase in P-NR2B levels in the lateral striatum, as expected (Quintana et al., 2010; Oh et al., 1998; Dunah et al., 2000), whereas STN-HFS did not. This striatal increase was greater and extended to the medial part of the striatum when CP-101,606 was administered with L-DOPA. We expected dyskinesia to be inhibited in these conditions, but it was instead increased, with the triggering of additional rotational behavior. In animal models of LID and motor fluctuations, the pharmacological blockade of NR2B has produced variable results. The NR2B-selective antagonists Co 101244 and $\mathrm{Cl}-1041$ have been shown to decrease LID in macaques (Blanchet et al., 2004; Hadj Tahar et al., 2004; Morissette et al., 2006), whereas CP-101,606 exacerbated LID in the rat (data presented here) and marmoset (Nash et al., 2004). CP-101,606 prevented L-DOPA-induced wearing-off fluctuations in 6OHDA-lesioned rats (Wessell et al., 2004). However, in the same animal model, the NR2B antagonists Ro256981 and Ro631908 failed to improve L-DOPA-induced AIMs (Rylander et al., 2009). Information about the specific site of action of these antagonists is required, because NR2B subunits are widely distributed throughout the brain (Loftis and Janowsky, 2003) and both the striatum and the STN are known to be involved in the induction of dyskinesia (Papa et al., 1995; Benabid et al., 2000; Greenamyre et al., 2001). These pharmacological data suggest that the basal ganglia subcircuits underlying dyskinesia driven by acute STN-HFS and chronic L-DOPA treatments might be different (STN-EP for the former, striatum-EP for the later), although we cannot exclude the possibility that these results simply reflect large differences in the antidyskinetic dose of CP-101,606 between these models ( 3 and $10 \mathrm{mg} / \mathrm{kg}$ in Quintana et al., 2010 compared to $3 \mathrm{mg} / \mathrm{kg}$ in the present study). Finally, it would be interesting to determine whether the transient nature of forelimb dyskinesia under STN-HFS is linked to the absence of striatal reactive NR2B under dyskinesiogenic stimulation, given that the striatum plays a key role in L-DOPA priming mechanisms. However, other groups found spontaneous LID that may not require priming i.e 6-OHDA-lesioned rats treated by intrastriatal graft of embryonic mesencephalic neurons (Soderstrom et al., 2008; Steece-Collier et al., 2009). These graft-induced dyskinesias are also influenced by glutamate (Soderstrom et al., 2008, 2010) and we cannot excluded that $5 \mathrm{HT} 1 \mathrm{~A}$ and D2 receptors found on cortico-striatal neurons also modify LID, suggesting that probably other subtile mechanisms should be considered for interpretation of these findings.

\section{STN-HFS-induced dyskinesia sheds light on the mechanisms of action of HFS}

Our results demonstrate that the inappropriate use of STN-HFS may result in the induction of dyskinesia. Our behavioral observations raise questions about the mechanism of action of HFS. Similar abnormal movements have been observed after spontaneous or experimental STN lesioning (Carpenter et al., 1950; Hammond et al., 1979; Hamada and DeLong, 1992; Guridi and Obeso, 2001). As the induction of dyskinesia and clinical improvements in Parkinsons disease symptoms observed after HFS (Benazzouz et al., 1993; Pollak et al., 1993; Limousin et al., 1995; Benabid et al., 2000) are similar to the results 
of subthalamotomy (Bergman et al., 1990; Aziz et al., 1991), it has been suggested that HFS is inhibitory. However, electrophysiological, neurochemical and gene expression studies have indicated that HFS induces complex events in the basal ganglia network, not all of which are similar to the effects of subthalamotomy. For example, a decrease in the firing state of the neurons of the stimulated site has been observed after HFS (Benazzouz et al., 1995, 2000; Tai et al., 2003), whereas activation has been reported for the axon of the projection site of the stimulated nucleus (Anderson et al., 2003; Hashimoto et al., 2003, Gradinaru et al., 2009). Decreases in Col and GAD67 levels or their normalization in the STN have also been reported, suggesting an inhibitory action of STN-HFS applied at therapeutic intensity (Benazzouz et al., 2004; Salin et al., 2002; Bacci et al., 2004). However, STN-HFS increases extracellular glutamate levels in the SNr and GP of naive rats, suggesting that it may play have an activating role (Windels et al., 2000, 2003, 2005). In addition, STN-HFS at an intensity inducing dyskinesia, increased basal extracellular levels of glutamate in the $\mathrm{SNr}$ of both naive and 6-OHDA rats, reflecting STN hyperactivity. In contrast, STN-HFS at half this intensity did not affect glutamate levels in the SNr in intact or 6-OHDA rats, but increased GABA levels in 6-OHDA rats only. (Boulet et al., 2006). Dual effects of HFS, depending on the intensity of stimulation, have also been observed in electrophysiological studies (Maurice et al., 2003). Our results, obtained at high intensity (resulting in the induction of dyskinesia), shown an increase in NR2B phosphorylation in the STN and EP, reflecting an increase in glutamatergic activity in these structures. Thus, the mechanisms of action of the HFS seem to differ between anti-akinetic and prodyskinetic intensities.

In conclusion, although very little is known about changes in glutamate receptors associated with STN-HFS, a vast literature has addressed the expression, phosphorylation state, and subcellular distribution of specific subtypes of glutamate receptors in animal models of LID. Rat models of STN-HFS-induced dyskinesia have been introduced only recently, therefore much remains to be done to unravel their underlying pathophysiology. A comparison between LID and STN-HFS-induced dyskinesias is likely to improve our understanding of the mechanisms triggering the expression of abnormal involuntary movements and the associated plastic responses. By comparing here the two models of dyskinesias we revealed common pathophysiological features that may guide future therapeutic strategies. One prominent feature is a dysregulation of extracellular glutamate homeostasis in the STN- GPi/SNr network, which has both glial and neuronal components. In the present work, we show that DA neuron lesions affected NR2B regulation in the SNr, but not in the other nuclei of the basal ganglia network. Only the L-DOPA dyskinesiogenic treatment induced hyperphosphorylation of the $\mathrm{Tyr}^{1472}$ residue of $\mathrm{NR} 2 \mathrm{~B}$, in the striatum ipsilateral to the 6-OHDA lesion, whereas both L-DOPA and STN-HFS dyskinesiogenic treatments induced NR2B hyperphosphorylation in the ipsilateral STN and bilaterally in the EP, but not in the SNr. Determining the role of this ectopic source of glutamate in animal models of PD and LID will be an exciting task for future studies. 


\section{References}

Ahlskog JE, Muenter MD (2001) Frequency of L-DOPA-related dyskinesias and motor fluctuations as estimated from the cumulative literature. Mov. Disord. 16(3): 448-458.

Anderson ME, Postupna N, Ruffo M (2003) Effects of high-frequency stimulation in the internal globus pallidus on the activity of thalamic neurons in the awake monkey. $\mathrm{J}$ Neurophysiol 89:1150-1160.

Andersson M, Hilbertson A, Cenci MA (1999) Striatal fosB expression is causally linked with I-DOPA-induced abnormal involuntary movements and the associated upregulation of striatal prodynorphin mRNA in a rat model of Parkinson's disease. Neurobiol Dis 6:461-474.

Aubert I, Guigoni C, Li Q, Dovero S, Bioulac BH, Gross CE, Crossman AR, Bloch B, Bezard $E$ (2007) Enhanced preproenkephalin-B-derived opioid transmission in striatum and subthalamic nucleus converges upon globus pallidus internalis in L-3,4dihydroxyphenylalanine-induced dyskinesia. Biol Psychiatry 61:836-844.

Aziz TZ, Peggs D, Sambrook MA, Crossman AR (1991) Lesion of the subthalamic nucleus for the alleviation of 1-methyl-4-phenyl-1,2,3,6-tetrahydropyridine (MPTP)-induced parkinsonism in the primate. Mov Disord 6:288-292.

Bacci JJ, Absi el H, Manrique C, Baunez C, Salin P, Kerkerian-Le Goff L (2004) Differential effects of prolonged high frequency stimulation and of excitotoxic lesion of the subthalamic nucleus on dopamine denervation-induced cellular defects in the rat striatum and globus pallidus. Eur J Neurosci 20:3331-3341.

Barbeau A (1969) L-dopa therapy in Parkinson's disease: a critical review of nine years' experience. Can Med Assoc J 101:59-68.

Bejjani B, Damier P, Arnulf I, Bonnet AM, Vidailhet M, Dormont D, Pidoux B, Cornu P, Marsault C, Agid Y (1997) Pallidal stimulation for Parkinson's disease. Two targets? Neurology 49:1564-1569.

Benabid AL, Benazzouz A, Limousin P, Koudsie A, Krack P, Piallat B, Pollak P (2000) Dyskinesias and the subthalamic nucleus. Ann Neurol 47:S189-192.

Benazzouz A, Piallat B, Pollak P, Benabid AL (1995) Responses of substantia nigra pars reticulata and globus pallidus complex to high frequency stimulation of the subthalamic nucleus in rats: electrophysiological data. Neurosci Lett 189:77-80.

Benazzouz A, Gross C, Feger J, Boraud T, Bioulac B (1993) Reversal of rigidity and improvement in motor performance by subthalamic high-frequency stimulation in MPTP-treated monkeys. Eur J Neurosci 5:382-389.

Benazzouz A, Gao DM, Ni ZG, Piallat B, Bouali-Benazzouz R, Benabid AL (2000) Effect of high-frequency stimulation of the subthalamic nucleus on the neuronal activities of the substantia nigra pars reticulata and ventrolateral nucleus of the thalamus in the rat. Neuroscience 99:289-295.

Benazzouz A, Tai CH, Meissner W, Bioulac B, Bezard E, Gross C (2004) High-frequency stimulation of both zona incerta and subthalamic nucleus induces a similar normalization of basal ganglia metabolic activity in experimental parkinsonism. Faseb $\mathrm{J}$ 18:528-530.

Bergman H, Wichmann T, DeLong MR (1990) Reversal of experimental parkinsonism by lesions of the subthalamic nucleus. Science 249:1436-1438.

Beurrier C, Bezard E, Bioulac B, Gross C (1997) Subthalamic stimulation elicits hemiballismus in normal monkey. Neuroreport 8:1625-1629.

Bibbiani F, Oh JD, Kielaite A, Collins MA, Smith C, Chase TN. (2005) Combined blockade of AMPA and NMDA glutamate receptors reduces L-DOPA-induced motor complications in animal models of PD. Exp Neurol 196(2):422-9.

Birkmayer W, Hornykiewicz O (1961) [The L-3,4-dioxyphenylalanine (DOPA)-effect in Parkinson-akinesia.]. Wien Klin Wochenschr 73:787-788.

Blanchet PJ, Calon F, Morissette M, Hadj Tahar A, Belanger N, Samadi P, Grondin R, Gregoire L, Meltzer L, Di Paolo T, Bedard PJ (2004) Relevance of the MPTP primate 
model in the study of dyskinesia priming mechanisms. Parkinsonism Relat Disord 10:297-304.

Blandini F, Greenamyre JT, Fancellu R, Nappi G (2001) Blockade of subthalamic glutamatergic activity corrects changes in neuronal metabolism and motor behavior in rats with nigrostriatal lesions. Neurol Sci 22:49-50.

Boraud T, Bezard E, Bioulac B, Gross CE (2001) Dopamine agonist-induced dyskinesias are correlated to both firing pattern and frequency alterations of pallidal neurones in the MPTP-treated monkey. Brain 124:546-557.

Boraud T, Bezard E, Guehl D, Bioulac B, Gross C (1998) Effects of L-DOPA on neuronal activity of the globus pallidus externalis $(\mathrm{GPe})$ and globus pallidus internalis (GPi) in the MPTP-treated monkey. Brain Res 787:157-160.

Boulet S, Lacombe E, Carcenac C, Feuerstein C, Sgambato-Faure V, Poupard A, Savasta M (2006) Subthalamic stimulation-induced forelimb dyskinesias are linked to an increase in glutamate levels in the substantia nigra pars reticulata. J Neurosci 26:10768-10776.

Bruet N, Windels F, Carcenac C, Feuerstein C, Bertrand A, Poupard A, Savasta M (2003) Neurochemical mechanisms induced by high frequency stimulation of the subthalamic nucleus: increase of extracellular striatal glutamate and GABA in normal and hemiparkinsonian rats. J Neuropath Exp Neur 62: 1228-1240.

Calabresi P, Mercuri NB, Sancesario G, Bernardi G (1993) Electrophysiology of dopaminedenervated striatal neurons. Implications for Parkinson's disease. Brain $116(\mathrm{Pt}$ 2):433-452.

Calon F, Rajput AH, Hornykiewicz O, Bedard PJ, Di Paolo T (2003) Levodopa-induced motor complications are associated with alterations of glutamate receptors in Parkinson's disease. Neurobiol Dis 14:404-416.

Calon F, Morissette M, Ghribi O, Goulet M, Grondin R, Blanchet PJ, Bedard PJ, Di Paolo T (2002) Alteration of glutamate receptors in the striatum of dyskinetic 1-methyl-4phenyl-1,2,3,6-tetrahydropyridine-treated monkeys following dopamine agonist treatment. Prog Neuropsychopharmacol Biol Psychiatry 26:127-138.

Carpenter MB, Whittier JR, Mettler FA (1950) Analysis of choreoid hyperkinesia in the Rhesus monkey; surgical and pharmacological analysis of hyperkinesia resulting from lesions in the subthalamic nucleus of Luys. J Comp Neurol 92:293-331.

Cenci MA, Lindgren HS (2007) Advances in understanding L-DOPA-induced dyskinesia. Curr Opin Neurobiol 17:665-671.

Cenci MA, Lee CS, Bjorklund A (1998) L-DOPA-induced dyskinesia in the rat is associated with striatal overexpression of prodynorphin- and glutamic acid decarboxylase mRNA. Eur J Neurosci 10:2694-2706.

Chase TN, Oh JD (2000) Striatal dopamine- and glutamate-mediated dysregulation in experimental parkinsonism. Trends Neurosci 23:S86-91.

Chen R, Garg RR, Lozano AM, Lang AE (2001) Effects of internal globus pallidus stimulation on motor cortex excitability. Neurology 56:716-723.

Dekundy A, Lundblad M, Danysz W, Cenci MA (2007) Modulation of L-DOPA-induced abnormal involuntary movements by clinically tested compounds: further validation of the rat dyskinesia model. Behav Brain Res. 179(1):76-89.

Del Dotto P, Pavese N, Gambaccini G, Bernardini S, Metman LV, Chase TN, Bonuccelli U (2001) Intravenous amantadine improves levadopa-induced dyskinesias: an acute double-blind placebo-controlled study. Mov Disord. 16(3):515-20.

Dunah AW, Wang Y, Yasuda RP, Kameyama K, Huganir RL, Wolfe BB, Standaert DG (2000) Alterations in subunit expression, composition, and phosphorylation of striatal $\mathrm{N}$-methyl-D-aspartate glutamate receptors in a rat 6-hydroxydopamine model of Parkinson's disease. Mol Pharmacol 57:342-352. 
El Atifi-Borel M, Buggia-Prevot V, Platet N, Benabid AL, Berger F, Sgambato-Faure V (2009) De novo and long-term I-Dopa induce both common and distinct striatal gene profiles in the hemiparkinsonian rat. Neurobiol Dis 34:340-350.

Greenamyre JT (2001) Glutamatergic influences on the basal ganglia. Clin Neuropharmacol 24:65-70.

Gradinaru V, Mogri M, Thompson KR, Henderson JM, Deisseroth K (2009) Optical deconstruction of parkinsonian neural circuitry. Science 324:354-359.

Gubellini P, Picconi B, Bari M, Battista N, Calabresi P, Centonze D, Bernardi G, Finazzi-Agro A, Maccarrone M (2002) Experimental parkinsonism alters endocannabinoid degradation: implications for striatal glutamatergic transmission. J Neurosci 22:69006907.

Guridi J, Obeso JA (2001) The subthalamic nucleus, hemiballismus and Parkinson's disease: reappraisal of a neurosurgical dogma. Brain 124:5-19.

Guridi J, Herrero MT, Luquin MR, Guillen J, Ruberg M, Laguna J, Vila M, Javoy-Agid F, Agid Y, Hirsch E, Obeso JA (1996) Subthalamotomy in parkinsonian monkeys. Behavioural and biochemical analysis. Brain 119 ( Pt 5):1717-1727.

Hadj Tahar A, Gregoire L, Darre A, Belanger N, Meltzer L, Bedard PJ (2004) Effect of a selective glutamate antagonist on L-dopa-induced dyskinesias in drug-naive parkinsonian monkeys. Neurobiol Dis 15:171-176.

Hallett PJ, Dunah AW, Ravenscroft P, Zhou S, Bezard E, Crossman AR, Brotchie JM, Standaert DG (2005) Alterations of striatal NMDA receptor subunits associated with the development of dyskinesia in the MPTP-lesioned primate model of Parkinson's disease. Neuropharmacology 48:503-516.

Hamada I, DeLong MR (1992) Excitotoxic acid lesions of the primate subthalamic nucleus result in transient dyskinesias of the contralateral limbs. J Neurophysiol 68:18501858.

Hammond C, Feger J, Bioulac B, Souteyrand JP (1979) Experimental hemiballism in the monkey produced by unilateral kainic acid lesion in corpus Luysii. Brain Res 171:577580.

Hashimoto T, Elder CM, Okun MS, Patrick SK, Vitek JL (2003) Stimulation of the subthalamic nucleus changes the firing pattern of pallidal neurons. J Neurosci 23:1916-1923.

Hirsch EC, Perier C, Orieux G, Francois C, Feger J, Yelnik J, Vila M, Levy R, Tolosa ES, Marin C, Trinidad Herrero M, Obeso JA, Agid Y (2000) Metabolic effects of nigrostriatal denervation in basal ganglia. Trends Neurosci 23:S78-85.

Hurley MJ, Jackson MJ, Smith LA, Rose S, Jenner P (2005) Immunoautoradiographic analysis of NMDA receptor subunits and associated postsynaptic density proteins in the brain of dyskinetic MPTP-treated common marmosets. Eur J Neurosci 21:32403250 .

Jonkers N, Sarre S, Ebinger G, Michotte Y (2002) MK801 suppresses the L-DOPA-induced increase of glutamate in striatum of hemi-Parkinson rats. Brain Res 926:149-155.

Krack P, Pollak P, Limousin P, Benazzouz A, Deuschl G, Benabid AL (1999) From off-period dystonia to peak-dose chorea. The clinical spectrum of varying subthalamic nucleus activity. Brain 122 ( Pt 6):1133-1146.

Krack P, Batir A, Van Blercom N, Chabardes S, Fraix V, Ardouin C, Koudsie A, Limousin PD, Benazzouz A, LeBas JF, Benabid AL, Pollak P (2003) Five-year follow-up of bilateral stimulation of the subthalamic nucleus in advanced Parkinson's disease. $\mathrm{N}$ Engl $\mathrm{J}$ Med 349:1925-1934.

Lacombe E, Khaindrava V, Melon C, Oueslati A, Kerkerian-Le Goff L, Salin P (2009) Different functional basal ganglia subcircuits associated with anti-akinetic and dyskinesiogenic effects of antiparkinsonian therapies. Neurobiol Dis 36:116-125. 
Limousin P, Pollak P, Hoffmann D, Benazzouz A, Perret JE, Benabid AL (1996) Abnormal involuntary movements induced by subthalamic nucleus stimulation in parkinsonian patients. Mov Disord 11:231-235.

Limousin P, Pollak P, Benazzouz A, Hoffmann D, Le Bas JF, Broussolle E, Perret JE, Benabid AL (1995) Effect of parkinsonian signs and symptoms of bilateral subthalamic nucleus stimulation. Lancet 345:91-95.

Lindefors N, Ungerstedt U (1990) Bilateral regulation of glutamate tissue and extracellular levels in caudate-putamen by midbrain dopamine neurons. Neurosci Lett 115:248252.

Loftis JM, Janowsky A (2003) The N-methyl-D-aspartate receptor subunit NR2B: localization, functional properties, regulation, and clinical implications. Pharmacol Ther 97:55-85.

Maurice N, Thierry AM, Glowinski J, Deniau JM (2003) Spontaneous and evoked activity of substantia nigra pars reticulata neurons during high-frequency stimulation of the subthalamic nucleus. J Neurosci 23:9929-9936.

Menegoz M, Lau LF, Herve D, Huganir RL, Girault JA (1995) Tyrosine phosphorylation of NMDA receptor in rat striatum: effects of 6-OH-dopamine lesions. Neuroreport 7:125128.

Morissette M, Dridi M, Calon F, Hadj Tahar A, Meltzer LT, Bedard PJ, Di Paolo T (2006) Prevention of levodopa-induced dyskinesias by a selective NR1A/2B N-methyl-Daspartate receptor antagonist in parkinsonian monkeys: implication of preproenkephalin. Mov Disord 21:9-17.

Moro E, Esselink RJ, Benabid AL, Pollak P (2002) Response to levodopa in parkinsonian patients with bilateral subthalamic nucleus stimulation. Brain 125:2408-2417.

Nash JE, Ravenscroft P, McGuire S, Crossman AR, Menniti FS, Brotchie JM (2004) The NR2B-selective NMDA receptor antagonist CP-101,606 exacerbates L-DOPAinduced dyskinesia and provides mild potentiation of anti-parkinsonian effects of LDOPA in the MPTP-lesioned marmoset model of Parkinson's disease. Exp Neurol 188:471-479.

Nutt JG, Gunzler SA, Kirchhoff T, Hogarth P, Weaver JL, Krams M, Jamerson B, Menniti FS, Landen JW (2008) Effects of a NR2B selective NMDA glutamate antagonist, CP101,606, on dyskinesia and Parkinsonism. Mov Disord 23(13):1860-1866.

O'Dell SJ, Marshall JF (1996) Chronic L-dopa alters striatal NMDA receptors in rats with dopaminergic injury. Neuroreport 7:2457-2461.

Oh JD, Russell DS, Vaughan CL, Chase TN (1998) Enhanced tyrosine phosphorylation of striatal NMDA receptor subunits: effect of dopaminergic denervation and L-DOPA administration. Brain Res 813:150-159.

Papa SM, Boldry RC, Engber TM, Kask AM, Chase TN (1995) Reversal of levodopa-induced motor fluctuations in experimental parkinsonism by NMDA receptor blockade. Brain Res 701:13-18.

Peretti-Renucci R, Feuerstein C, Manier M, Lorimier P, Savasta M, Thibault J, Mons N, Geffard M (1991) Quantitative image analysis with densitometry for immunohistochemistry and autoradiography of receptor binding sites--methodological considerations. J Neurosci Res 28:583-600.

Pollak P, Benabid AL, Gross C, Gao DM, Laurent A, Benazzouz A, Hoffmann D, Gentil M, Perret J (1993) [Effects of the stimulation of the subthalamic nucleus in Parkinson disease]. Rev Neurol (Paris) 149:175-176.

Porter RH, Greene JG, Higgins DS, Jr., Greenamyre JT (1994) Polysynaptic regulation of glutamate receptors and mitochondrial enzyme activities in the basal ganglia of rats with unilateral dopamine depletion. J Neurosci 14:7192-7199.

Putterman, D.B., Munhall, A.C., Kozell, L.B., Belknap, J.K., Johnson, S.W., 2007. Evaluation of levodopa dose and magnitude of dopamine depletion as risk factors for levodopainduced dyskinesia in a rat model of Parkinson's disease. J. Pharmacol. Exp. Ther. $323,277 \square 284$.

Quintana A, Melon C, Kerkerian-Le Goff L, Salin P, Savasta M, Sgambato-Faure V (2010) Forelimb dyskinesia mediated by high-frequency stimulation of the subthalamic 
nucleus is linked to rapid activation of the NR2B subunit of $\mathrm{N}$-methyl-D-aspartate receptors. Eur J Neurosci 32:423-434.

Rascol O, Fabre N (2001) Dyskinesia: L-dopa-induced and tardive dyskinesia. Clin Neuropharmacol 24:313-323.

Rylander D, Recchia A, Mela F, Dekundy A, Danysz W, Cenci MA (2009) Pharmacological modulation of glutamate transmission in a rat model of L-DOPA-induced dyskinesia: effects on motor behavior and striatal nuclear signaling. J Pharmacol Exp Ther 330:227-235.

Salin P, Manrique C, Forni C, Kerkerian-Le Goff L (2002) High-frequency stimulation of the subthalamic nucleus selectively reverses dopamine denervation-induced cellular defects in the output structures of the basal ganglia in the rat. J Neurosci 22:51375148.

Sgambato-Faure V, Buggia V, Gilbert F, Levesque D, Benabid AL, Berger F (2005) Coordinated and spatial upregulation of arc in striatonigral neurons correlates with Ldopa-induced behavioral sensitization in dyskinetic rats. J Neuropathol Exp Neurol 64:936-947.

Sgambato-Faure V and Cenci MA (2012) Glutamatergic mechanisms in the dyskinesias induced by pharmacological dopamine replacement and deep brain stimulation for the treatment of Parkinson's disease. Prog Neurobiol 96(1):69-86. Epub 2011 Nov 3.

Soderstrom KE, Meredith G, Freeman TB, McGuire SO, Collier TJ, Sortwell CE, Wu Q, Steece-Collier K (2008) The synaptic impact of the host immune response in a parkinsonian allograft rat model: Influence on graft-derived aberrant behaviors. Neurobiol Dis 32:229-42.

Soderstrom KE, O'Malley JA, Levine ND, Sortwell CE, Collier TJ, Steece-Collier K.(2010) Impact of dendritic spine preservation in medium spiny neurons on dopamine graft efficacy and the expression of dyskinesias in parkinsonian rats. Eur $\mathrm{J}$ Neurosci. $31: 478-90$.

Soghomonian JJ (2006) L-DOPA-induced dyskinesia in adult rats with a unilateral 6-OHDA lesion of dopamine neurons is paralleled by increased c-fos gene expression in the subthalamic nucleus. Eur J Neurosci. 23(9):2395-403. Erratum in: Eur J Neurosci. 24(5):1505.

Steece-Collier K, Soderstrom KE, Collier TJ, Sortwell CE, Maries-Lad E (2009) Effect of levodopa priming on dopamine neuron transplant efficacy and induction of abnormal involuntary movements in parkinsonian rats. J Comp Neurol.515:15-30.

Su PC, Ma Y, Fukuda M, Mentis MJ, Tseng HM, Yen RF, Liu HM, Moeller JR, Eidelberg D (2001) Metabolic changes following subthalamotomy for advanced Parkinson's disease. Ann Neurol 50:514-520.

Tai CH, Boraud T, Bezard E, Bioulac B, Gross C, Benazzouz A (2003) Electrophysiological and metabolic evidence that high-frequency stimulation of the subthalamic nucleus bridles neuronal activity in the subthalamic nucleus and the substantia nigra reticulata. Faseb J 17:1820-1830.

Toda H, Hamani C, Lozano A (2004) Deep brain stimulation in the treatment of dyskinesia and dystonia. Neurosurg Focus 17:E2.

Wessell RH, Ahmed SM, Menniti FS, Dunbar GL, Chase TN, Oh JD (2004) NR2B selective NMDA receptor antagonist CP-101,606 prevents levodopa-induced motor response alterations in hemi-parkinsonian rats. Neuropharmacology 47:184-194.

Windels F, Carcenac C, Poupard A, Savasta M (2005) Pallidal origin of GABA release within the substantia nigra pars reticulata during high-frequency stimulation of the subthalamic nucleus. J Neurosci 25:5079-5086.

Windels F, Bruet N, Poupard A, Feuerstein C, Bertrand A, Savasta M (2003) Influence of the frequency parameter on extracellular glutamate and gamma-aminobutyric acid in substantia nigra and globus pallidus during electrical stimulation of subthalamic nucleus in rats. J Neurosci Res 72: 259-267. 
Windels F, Bruet N, Poupard A, Urbain N, Chouvet G, Feuerstein C, Savasta M (2000) Effects of high frequency stimulation of subthalamic nucleus on extracellular glutamate and GABA in substantia nigra and globus pallidus in the normal rat. Eur $\mathrm{J}$ Neurosci 12:4141-4146.

Wullner U, Standaert DG, Testa CM, Landwehrmeyer GB, Catania MV, Penney JB, Jr., Young $A B$ (1994) Glutamate receptor expression in rat striatum: effect of deafferentation. Brain Res 647:209-219.

Yelnik J, Damier P, Bejjani BP, Francois C, Gervais D, Dormont D, Arnulf I, A MB, Cornu P, Pidoux B, Agid $Y(2000)$ Functional mapping of the human globus pallidus: contrasting effect of stimulation in the internal and external pallidum in Parkinson's disease. Neuroscience 101:77-87. 


\section{Table and Figure legends}

Table 1: Effect of 6-OHDA lesions on optical density measurements of immunoreactive signals for P-NR2B, NR2B in the striatum, the STN, the EP and the SNr. ${ }^{* *} p<0.01$ vs. control group and $\$ \S p<0.01$ vs. the contralateral side. A two-way ANOVA analysis was performed and indicated that the [lesion] $\mathrm{x}$ [side] interaction played a significant role in determining P-NR2B levels in the $\operatorname{SNr}\left(F_{[\text {side] }(1,19)}=14.819, p_{[\text {side] }}=0.001 ; F_{[l e s i o n](1,11)}=6.658\right.$, $\left.p_{\text {[lesion] }}=0.02 ; F_{\text {[lesion x side](1,19) }}=4.506, p_{\text {[lesion } x \text { side] }}=0.05\right)$.

Figure 1: Extent of the 6-OHDA lesion and control of electrode location. (A and B) Representative photomicrographs of frontal sections stained for $\mathrm{TH}$ in the striatal and nigral regions. \# Lesioned side. (C) Quantification of the optical density of TH immunostaining in the striatum and substantia nigra pars compacta in the various groups of animals. ${ }^{* * *} p<$ 0.001 versus controls, i.e. unlesioned rats. (D) Schematic diagrams of electrode location in the STN for the one hour stimulated rats, according to the stereotaxic atlas of Paxinos and Watson (anteriority -3.6 to $-4.16 \mathrm{~mm}$ from bregma). (E) Representative photomicrograph of frontal section stained with cresyl violet illustrating the location of the electrode within the STN. Scale bars, $1 \mathrm{~mm}$ in panel A,B and $200 \mu \mathrm{m}$ in panel E. Abbreviations: $c p$, cerebral peduncle; HFS, high-frequency stimulation; Hi, hippocampus; $\mathrm{LH}$, lateral hypothalamic nucleus, SNc, substantia nigra pars compacta; ST, striatum; STN, subthalamic nucleus; Thal, thalamus.

Figure 2: Assessment of the dyskinetic behavior of 6-OHDA-lesioned rats treated by chronic L-DOPA administration. (A) Changes in total AIM score during the treatment. Post hoc analysis showed that AIMs severity was higher after the fourth session $(p<0.05)$. (B) Proportion of each subtype of AIMs during treatment. Abbreviations: AIMs, abnormal involuntary movements.

Figure 3: Effect of dyskinesiogenic L-DOPA and STN-HFS treatments on P-NR2B levels in the striatum. (A-C) Representative photomicrographs of P-NR2B staining on a striatal section from each experimental group. Note that HFS was applied acutely (for one hour), while LDOPA treatment was chronic (10 days). (D) Quantification of P-NR2B staining in the lesioned striatum after 6-OHDA lesioning, STN-HFS and L-DOPA. ${ }^{* * *} p<0.001$ vs. controls, ${ }^{\# \# \#} p<$ 0.001 vs. $6-\mathrm{OHDA},{ }^{£} p<0.05$ vs. medial striatum. Scale bar, $1 \mathrm{~mm}$. Abbreviations: cc, corpus callosum; HFS, high-frequency stimulation; Lat, lateral; Med, medial; Str, striatum; LV, lateral ventricle.

Two-way ANOVA analyses confirmed that neither STN-HFS nor L-DOPA affected NR2B levels in the striatum, which remained similar to those in the control and 6-OHDA groups (respectively $F_{[\text {[region](3,59) }}=0.446, p_{\text {[region] }}=0.721 ; F_{\text {[treatment](2,59) }}=0.444, p_{\text {[treatment] }}=0.644$; $F_{\text {[treatment } x \text { region] }(6,59)}=0.110, p_{\text {[treatment } x \text { region] }}=0.995$ for HFS and $F_{\text {[region] }(3,55)}=1.044, p_{\text {[region] }}=$ $0.383 ; F_{[\text {treatment(2,55) }}=0.533, p_{\text {[treatment] }}=0.591 ; F_{\text {[treatment } x \text { region](6,55) }}=0.501, p_{\text {[treatment } x \text { region] }}=$ 0.804 for L-DOPA; $n=4$ for 6 -OHDA, $n=7$ for control and L-DOPA and $n=6$ for HFS) (data not shown). Two-way ANOVA confirmed that HFS had no effect on P-NR2B expression $\left(F_{\text {[region](3,63) }}=0.274, p_{\text {[region] }}=0.844 ; F_{\text {[treatment](2,63) }}=0.381, p_{\text {[treatment] }}=0.685 ; F_{\text {[treatment } x \text { region](6,63) }}=\right.$ $0.164, p_{\text {[treatment } x \text { region] }}=0.985 ; n=6$ for control and $n=5$ for 6-OHDA and HFS). Moreover, an interaction between the treatment and the striatal region considered was detected $\left(F_{[\text {region] }(3,63)}\right.$ $=2.671, p_{\text {[region] }}=0.057 ; F_{[\text {treatment](2,63) }}=1.035, p_{\text {[treatment] }}=0.362 ; F_{\text {[treatment } x \text { region](6,63) }}=3.039$, $p_{\text {[treatment } x \text { region] }}=0.013 ; n=7$ for control and $n=6$ for 6-OHDA and L-DOPA).

Figure 4: Effect of dyskinesiogenic L-DOPA and STN-HFS treatments on P-NR2B and NR2B levels in the STN. Representative photomicrographs of P-NR2B (A-C) and NR2B (E$G)$ immunolabeling on subthalamic sections from each experimental group. Quantification of P-NR2B (D) and NR2B (H) immunolabeling after 6-OHDA lesioning, STN-HFS and L-DOPA. 
${ }^{*} p<0.05,{ }^{* * *} p<0.001$ vs. control; ${ }^{*} p<0.05,{ }^{\# \#} p<0.01$ vs. $6-O H D A$ and ${ }^{\S} p<0.01$ vs. contralateral side. Scale bar, $200 \mu \mathrm{m}$. Abbreviations: $\mathrm{cp}$, cerebral peduncle; HFS, highfrequnecy stimulation; STN, subthalamic nucleus; contra, contralateral; ipsi, ipsilateral.

Moreover, two-way ANOVA revealed the existence of an interaction between the treatment and the side $\left(F_{[\text {side] }(1,35)}=5.455, p_{\text {[side] }}=0.026 ; F_{\text {[treatment] }(2,35)}=3.930, p_{\text {[treatment] }}=0.030 ; F_{\text {[treatment }}\right.$ $x$ side] $(2,35)=4.976, p_{[\text {treatment } x \text { side] }}=0.014 ; n=7$ for control, $n=6$ for 6 -OHDA and $n=9$ for HFS). One-way ANOVA analysis showed that the ipsilateral P-NR2B levels to be significantly increased by L-DOPA ( $L-D O P A$ vs. control: $+160 \% ; F_{(1,15)}=5.909 ; p=0.015$;

Two-way ANOVA revealed a significant effect of the treatment $\left(F_{[\text {[ide](1,29) }}=0.524, p_{[\text {side] }}=\right.$ $0.476 ; F_{[\text {[reatment }(2,29)}=6.864, p_{[\text {treatment] }}=0.004 ; F_{[\text {[treatment } x \text { side }](2,29)}=0.593, p_{[\text {[reatment } x \text { side }]]}=$ $0.561)$.

Figure 5: Effect of dyskinesiogenic L-DOPA and STN-HFS treatments on P-NR2B and NR2B levels in the EP. Representative photomicrographs of P-NR2B (A-C) and NR2B (D-F) immunolabeling on entopeduncular sections from each experimental group. Quantification of P-NR2B (G) and NR2B (H) immunolabeling after 6-OHDA lesioning, STN-HFS and L-DOPA. Scale bar, $100 \mu \mathrm{m}$. ${ }^{*} p<0.05,{ }^{* *} p<0.01$ and ${ }^{* * *} p<0.001$ vs. control; ${ }^{\#} p<0.05$ and ${ }^{\# \#} p<$ 0.01 vs. 6-OHDA. Abbreviations: EP, entopeduncular nucleus; HFS, high-frequency stimulation; contra, contralateral; ipsi, ipsilateral.

Two-way ANOVA analysis revealed an effect treatment characterized by a bilateral activation of P-NR2B $(p<0.05$; Figure $5 \mathrm{G})$ in the HFS group $\left(F_{[\text {side] }(1,43)}=0.188, p_{\text {[side] }}=0.667\right.$; $F_{\text {[treatment](2,43) }}=6.723, p_{\text {[treatment] }}=0.003 ; F_{\text {[treatment } x \text { side] }(2,43)}=0.0769, p_{\text {[treatment } x \text { side] }}=0.926 ; n=7$ for control group, $n=6$ for 6-OHDA group and $n=9$ for HFS). Two-way ANOVA analyses $\left(F_{[\text {side] }[1,21)}=0.345, p_{\text {[side] }}=0.565 ; F_{\text {[treatment] }(2,21)}=0.996, p_{\text {[treatment] }}=0.391 ; F_{\text {[treatment } x \text { side] }[2,21)}=\right.$ $0.263, p_{[\text {treatment } x \text { side] }}=0.772$ for HFS and $F_{[\text {side] }[1,27)}=0.939, p_{[\text {side] }}=0.345 ; F_{\text {[treatment] }(2,27)}=0.481$, $p_{\text {[treatment] }}=0.626 ; F_{\text {[treatment } x \text { side] }(2,27)}=0.0377, p_{\text {[treatment } x \text { side] }}=0.963$ for L-DOPA; Figure $5 \mathrm{H}$ ).

Figure 6: Effect of dyskinesiogenic L-DOPA and STN-HFS treatments on P-NR2B and NR2B levels in the SNr. (A-C) Representative photomicrographs of P-NR2B immunolabeling on nigral section from each experimental group. Quantification of P-NR2B (D) and NR2B (E) immunolabeling after 6-OHDA lesioning, STN-HFS and L-DOPA. Scale bar, $100 \mu \mathrm{m} .{ }^{*} p<$ 0.05 and ${ }^{* *} p<0.01$ vs. control; $\$ \$ p<0.05$ and $\$ \S p<0.01$ vs. contralateral side. Abbreviations: HFS, high-frequency stimulation; contra, contralateral; ipsi, ipsilateral.

Figure 7: Effect of CP-101,606 on L-DOPA-induced motor behavior. (A) Total AIM score over the 10 days of treatment. (B) Proportion of the different AIM subtypes. (C) Total AIM score during an observation session on day 8 of treatment. (D) Number of contralateral rotations during the 10-day treatment period.

Two-way repeated measures ANOVA ([group] and [session]) revealed a significant difference between groups and observation sessions, and an interaction between these two factors $\left(F_{\text {[group] }(2,34)}=8.222, p_{\text {[group] }}=0.015 ; F_{\text {[session] }(5,34)}=11.224, p_{\text {[session] }}<0.001 ; F_{\text {[group } x}\right.$ session] $\left.(10,34)=5.573, p_{\text {[group } x \text { session] }}<0.001\right)$.

Two-way repeated measures ANOVA ([group] and [post-injection time]) detected significant differences between groups and observation time and an interaction between these factors $\left(F_{\text {[group] }(2,59)}=9.418, p_{\text {[group] }}=0.010 ; F_{\text {[time] }(5,59)}=12.958, p_{\text {[time] }}<0.001 ; F_{\text {[group } \times \text { time] }(10,59)}=\right.$ $\left.4.896, p_{\text {[group x time] }}<0.001\right)$.

Figure 8: Effect of CP-101,606 on total and phosphorylated NR2B levels in the basal ganglia. (A-B) Quantification of P-NR2B in the ipsilateral (A) and contralateral (B) striata after 6-OHDA lesioning, L-DOPA, and CP-101,606 plus L-DOPA. (C-D) Quantification of P-NR2B ipsilaterally (C) and contralaterally (D) in the STN, EP and 
SNr. ${ }^{*}$ vs. controls; ${ }^{\#}$ vs. $6-\mathrm{OHDA} ;{ }^{\$}$ vs. L-DOPA and ${ }^{\varepsilon}$ vs. medial striatum. ${ }^{*} p<0.05$; ${ }^{* *} p<0.01$; ${ }^{* * *} p<0.001$. Abbreviations: CP, CP-101,606; EP, entopeduncular nucleus; SNr, substantia nigra pars reticulate; STN, subthalamic nucleus. 

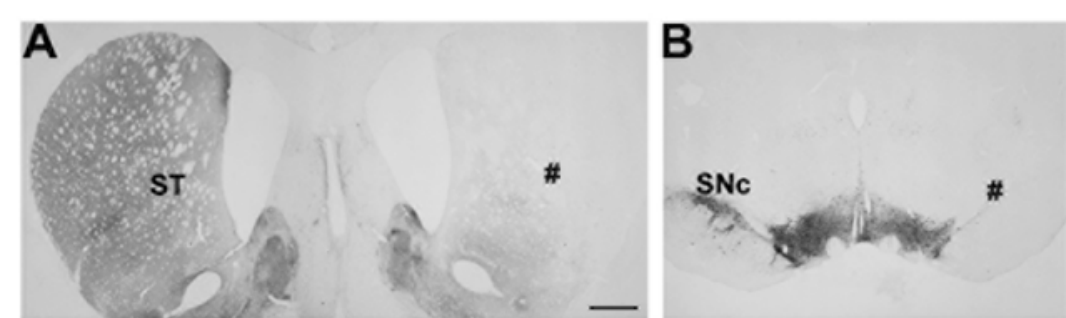

D

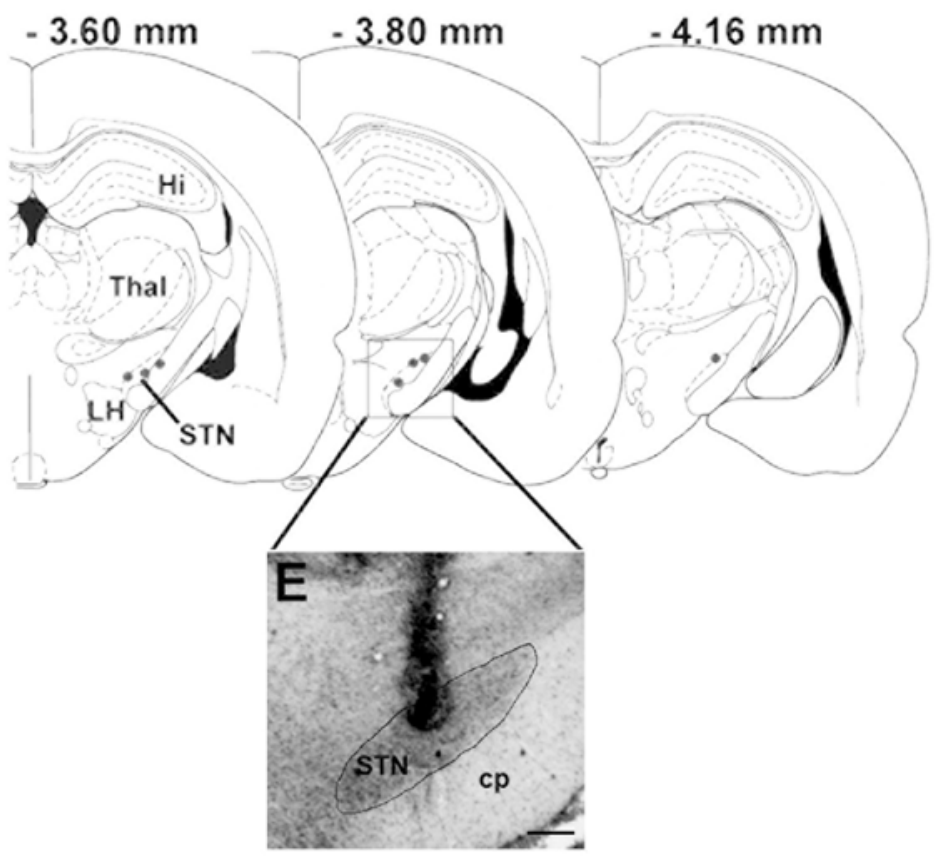

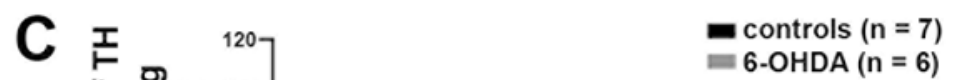
HFS $(n=9)$

$=$ L-DOPA $(n=6)$

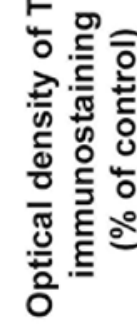

Striatum

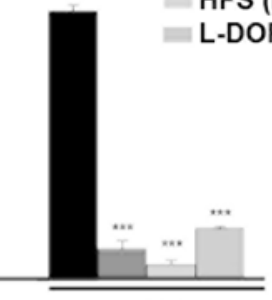

SNc 

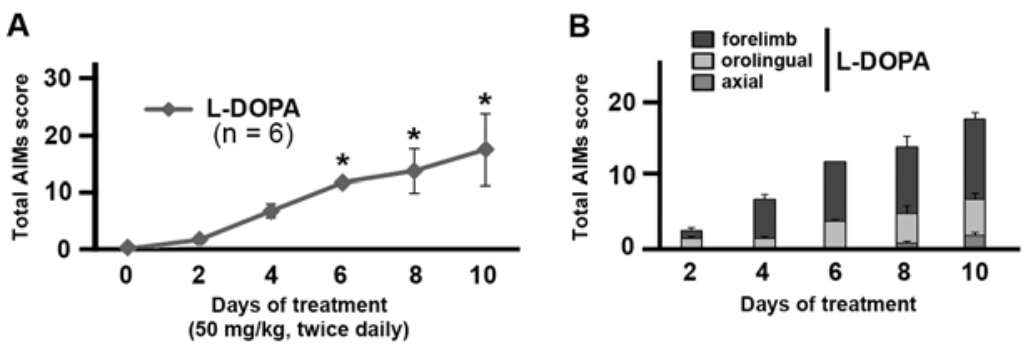


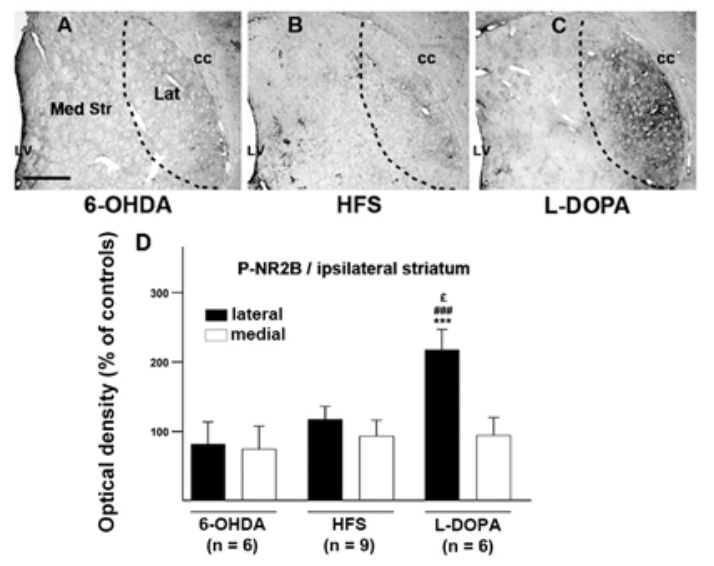



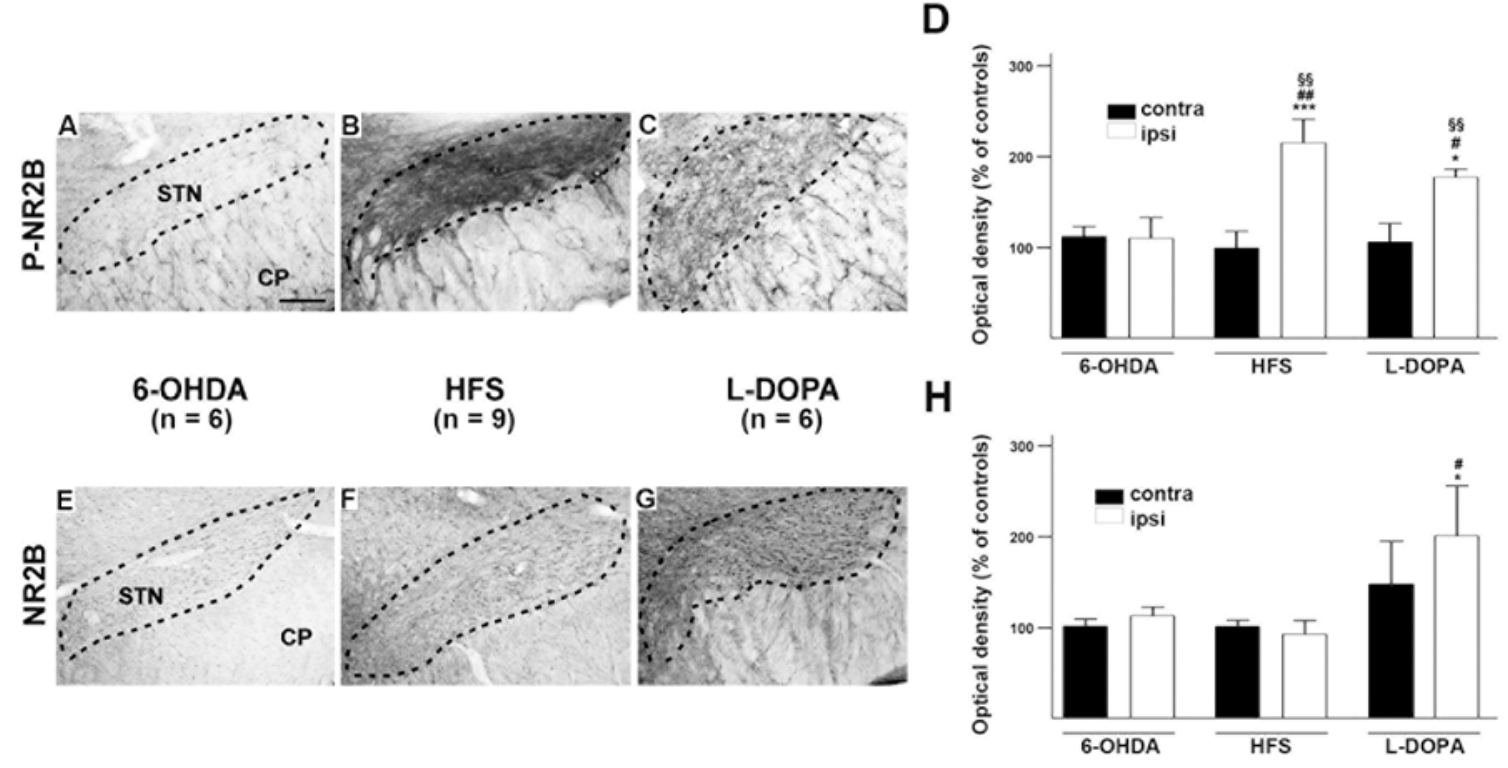


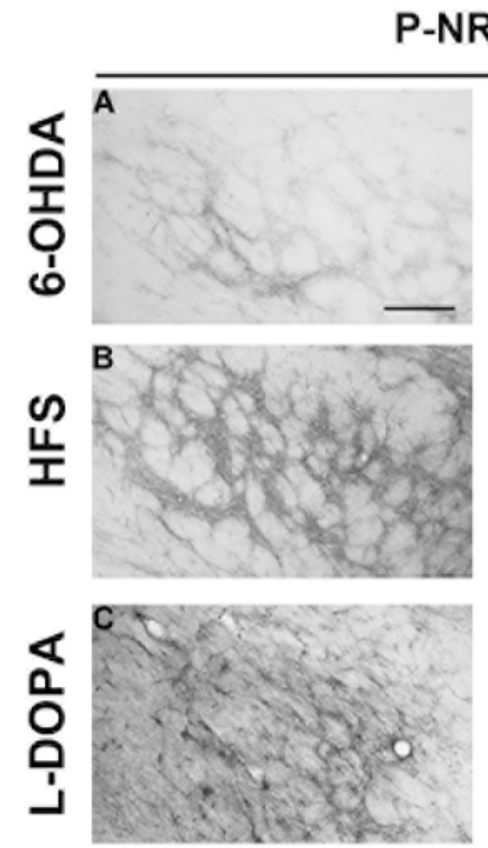

contra

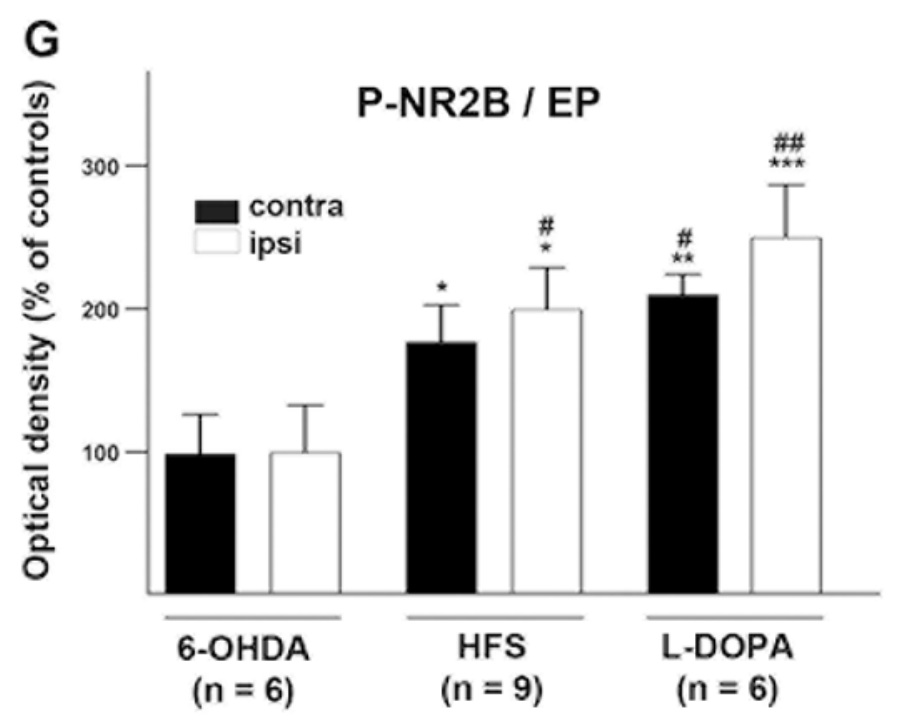

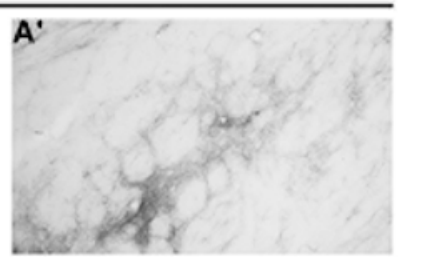
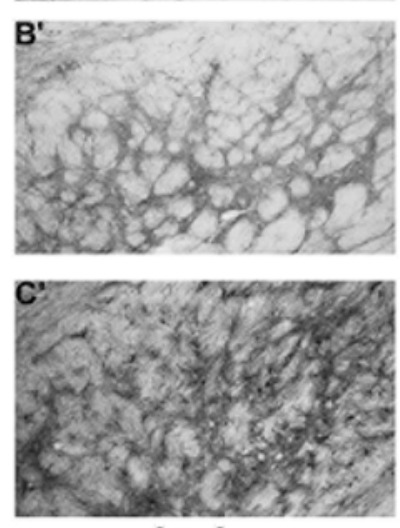

ipsi
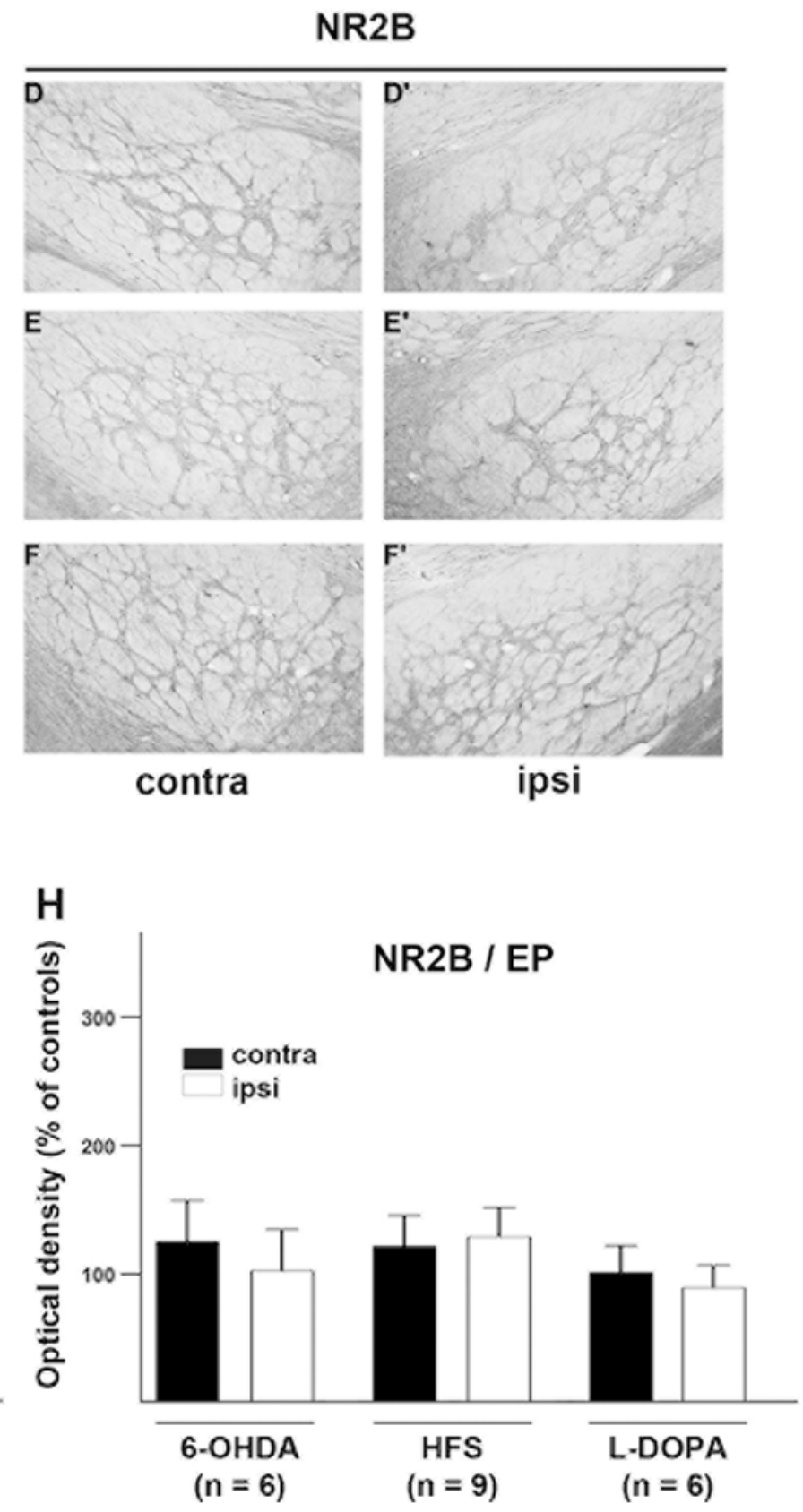


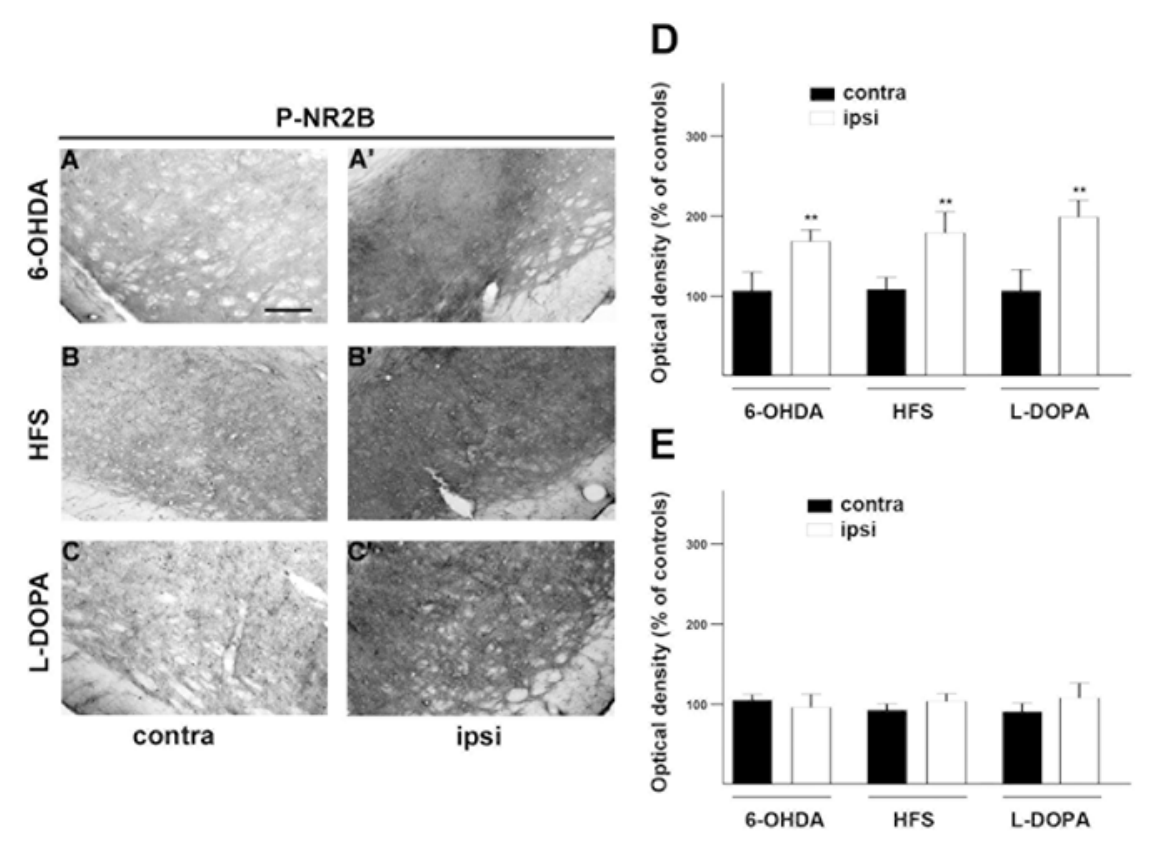


A

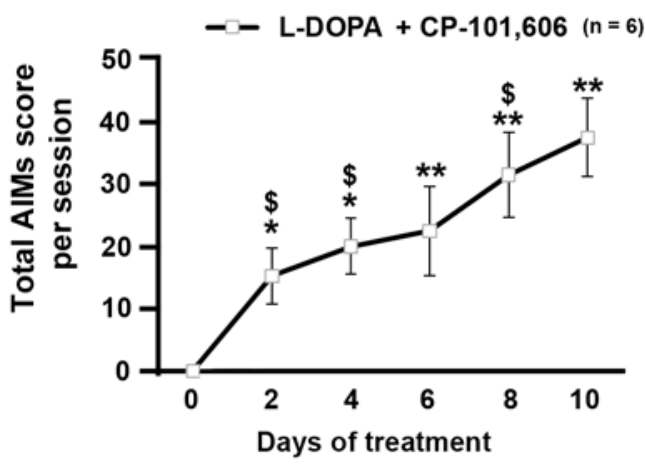

C<smiles>C=C[Te]OP(=O)(O)O</smiles>
- L-DOPA + CP-101,606

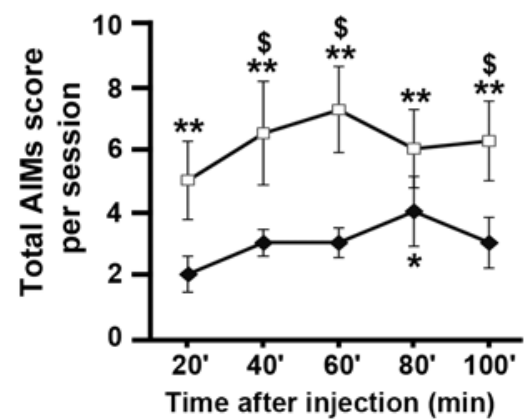

B
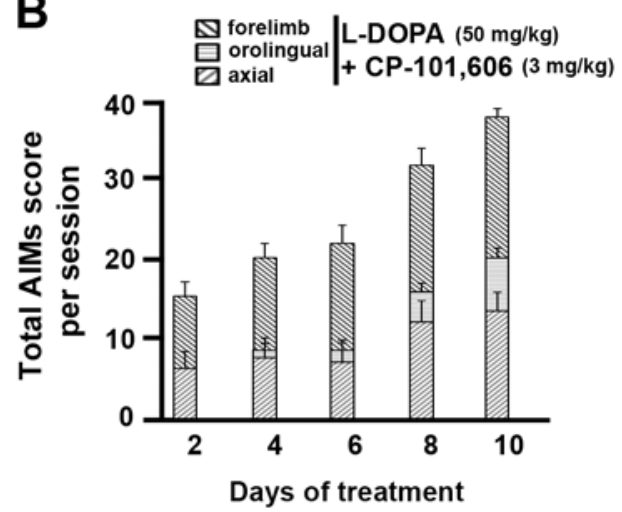

D
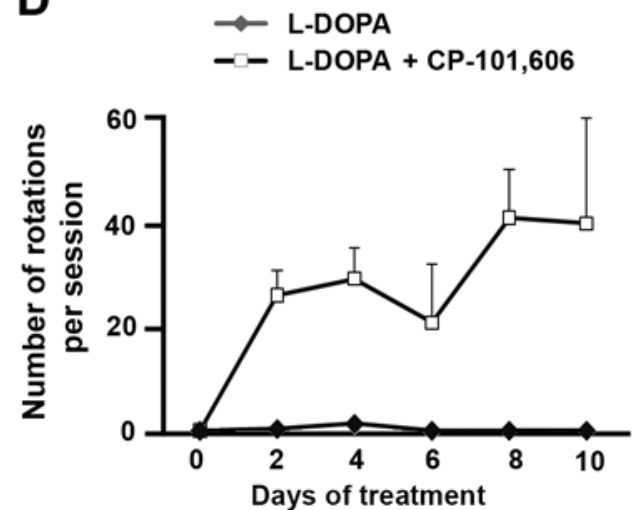


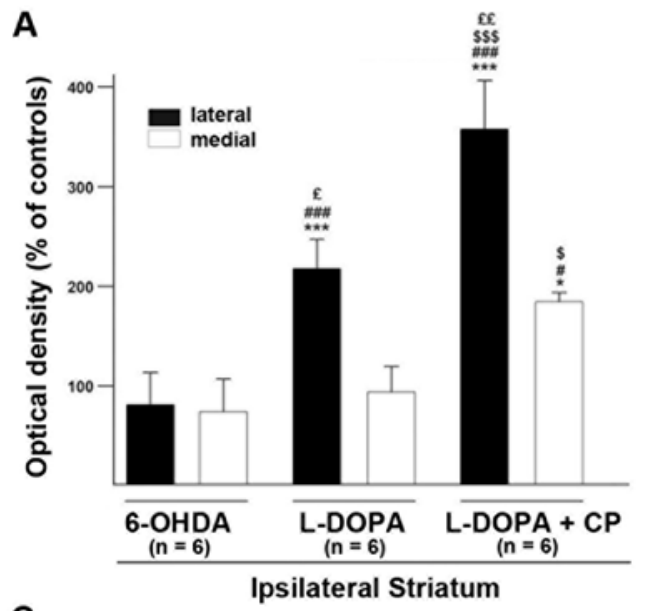

B
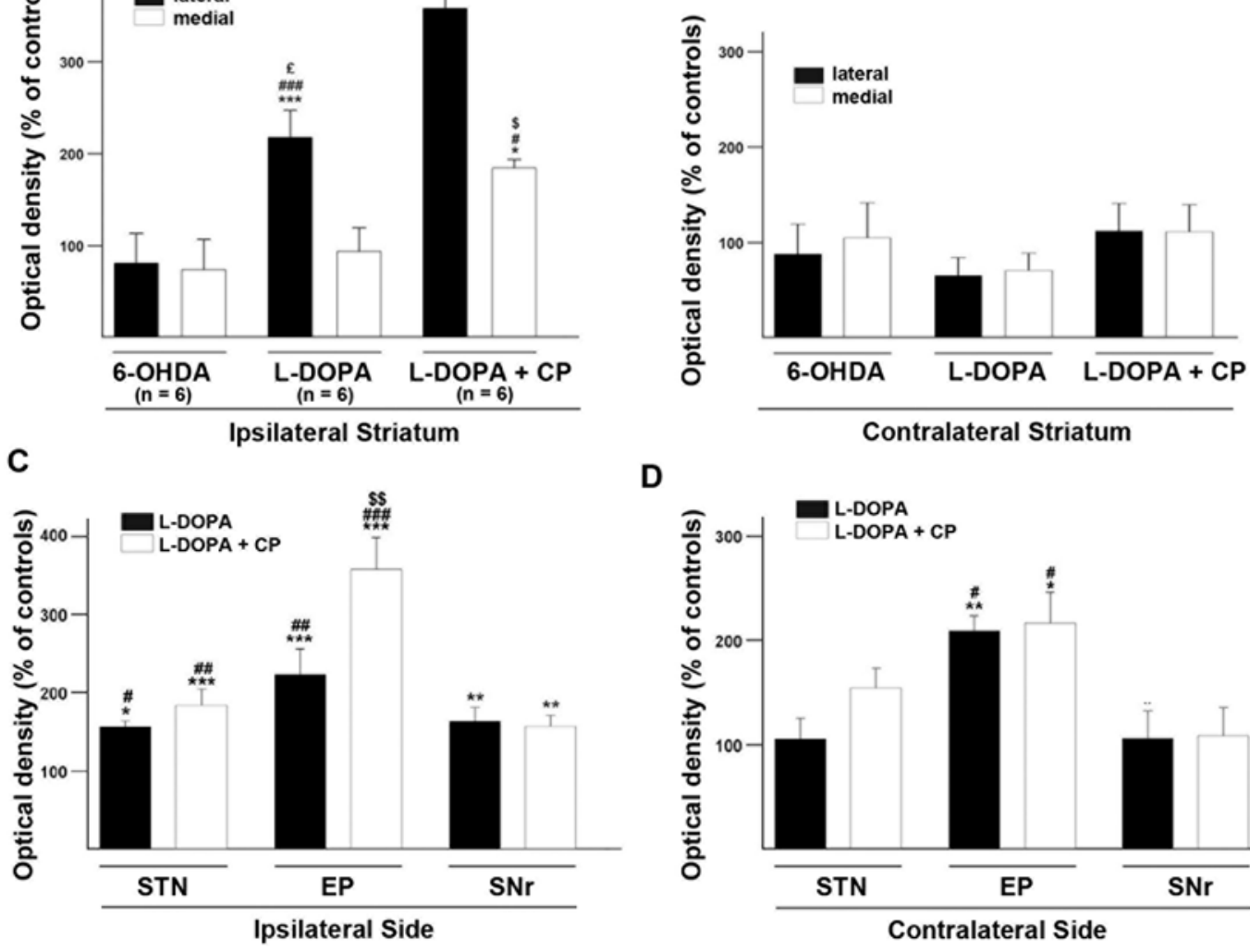

D

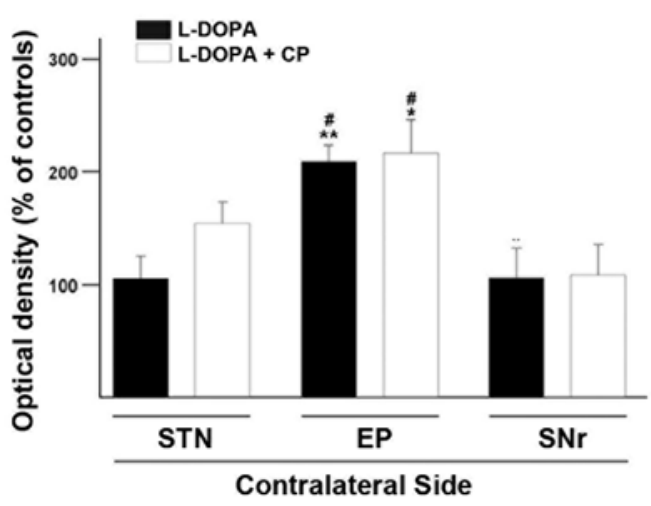

